\title{
THE POLITICAL ECONOMY OF INTERGENERATIONAL INCOME MOBILITY
}

\author{
ANDREA ICHINO, LOUKAS KARABARBOUNIS and ENRICO MORETTI*
}

The intergenerational elasticity of income is considered one of the best measures of the degree to which a society gives equal opportunity to its members. While much research has been devoted to measuring this reduced-form parameter, less is known about its underlying structural determinants. Using a model with exogenous talent endowments, endogenous parental investment in children, and endogenous redistributive institutions, we identify the structural parameters that govern the intergenerational elasticity of income. The model clarifies how the interaction between private and collective decisions determines the equilibrium level of social mobility. Two societies with similar economic and biological fundamentals may have vastly different degrees of intergenerational mobility depending on their political institutions. We offer empirical evidence in line with the predictions of the model. We conclude that international comparisons of intergenerational elasticity of income are not particularly informative about fairness without taking into account differences in politico-economic institutions. (JEL E24, J62, J68, P16)

\section{INTRODUCTION}

The intergenerational elasticity of income is generally considered one of the best summary measures of the degree to which a society gives equal opportunities of success to all its members, irrespective of their family background. Starting with pioneering work by Solon (1992) and Zimmerman (1992), the economic literature has made important advances on the question of how to measure this parameter using the GaltonBecker-Solon (GBS) regression:

$$
y_{\mathrm{s}}=a+\beta y_{\mathrm{f}}+u_{\mathrm{s}}
$$

*We would like to thank Alberto Alesina, Giacomo Calzolari, Ed Glaeser, John Hassler, Larry Katz, Mattia Nardotto, Sevi Rodriguez-Mora, and seminar participants at C6-Capri, ESSLE-CEPR 2008, Edinburgh University, Harvard and Sorbonne for useful discussions. We also thank two anonymous referees for their helpful suggestions.

Ichino: Professor of Economics, University of Bologna, Department of Economics, Bologna, Italy. Phone $(+39)$ 051-20-98-878 E-mail andrea.ichino@unibo.it

Karabarbounis: Assistant Professor of Economics and Neubauer Family Faculty Fellow, University of Chicago, Booth School of Business, Chicago, IL. Phone (+01) 773-834-8327 E-mail loukas.karabarbounis@ chicagobooth.edu

Moretti: Professor of Economics, University of CaliforniaBerkeley, Department of Economics, Berkeley, CA. Phone (+01) 510-642-6649 E-mail moretti@econ. berkeley.edu where $y_{\mathrm{s}}$ is son's log income and $y_{\mathrm{f}}$ is father's $\log$ income. A lower $\beta$ denotes a smaller association between father's and son's income and therefore a higher degree of social mobility. As such, a lower $\beta$ is often interpreted as being a desirable feature of a society.

While we have learned a lot about how to estimate this reduced-form parameter, less progress has been made on understanding its underlying structural determinants. What does $\beta$ actually measure? Is a lower $\beta$ necessarily more desirable? Important progress on these questions has been made by Becker and Tomes (1979), who have shown how the intergenerational persistence of income reflects both "nature and nurture." In their model individuals are assigned talent by nature, and parents can add to that talent by privately investing in their children. The intergenerational transmission of income is therefore a combination of exogenous biological factors and endogenous

\section{ABBREVIATIONS}

ELF: Ethnolinguistic Fractionalization

GBS: Galton-Becker-Solon

GDP: Gross Domestic Product

VAT: Value Added Tax

WVS: World Value Surveys 
optimizing behavior of parents. However, the Becker and Tomes model generally ignores the role of redistributive policies and their deeper determinants. Redistributive policies have the potential to play an important role in determining how income is transmitted from one generation to the next. For example, public education can significantly affect economic opportunities of individuals who come from disadvantaged socioeconomic backgrounds. At the same time, it can also affect parents' incentives to privately invest in their children human capital, both directly and through the disincentive effect of taxes. More in general, most redistributive policies - including taxation, affirmative action, welfare programs, subsidies that target poor individuals - potentially affect the intergenerational elasticity of income. While some studies have highlighted the role of public policies as a determinant of social mobility, most existing studies take these policies as exogenous.

In this paper we use a model with exogenous talent endowments, endogenous parental investment in children and endogenous redistributive institutions, to identify the structural parameters that govern the intergenerational mobility. Our framework extends the Becker and Tomes framework and clarifies how the interaction between private and collective decisions determines the equilibrium level of social mobility. The model allows for a structural interpretation of the widely studied parameter $\beta$. This is important because it allows a better understanding of the deeper politico-economic determinants of intergenerational mobility and the role of public policy. The model also shows how we should interpret and rank differences over time and across countries in $\beta$. Since redistributive policies generate a trade-off between insurance and incentives, the optimal $\beta$ is not necessarily zero for all societies. In addition, international comparisons of intergenerational elasticity of income are shown to be not particularly informative about fairness without taking into account differences in politico-economic institutions. The predictions of the model seem generally consistent with the empirical evidence.

Our framework focuses on how parents transfer economic endowments to their children through private and collective investment in their human capital. Before having children, parents know their own genetic ability but are uncertain about their children's genetic ability. Consistent with Becker and Tomes (1979) and Loury (1981), parents can decide to invest privately in the human capital of their children, given an exogenous degree of transmission of genetic ability. This private investment offsets some of the risk of having low genetic ability, thus reducing the probability that an individual might turn out to have low productivity and therefore low income. Since private investment can offset some but not all of the genetic risk, parents "under the veil of ignorance" have an incentive to collectively create public institutions that provide further insurance against the risk of low genetic ability. A natural example of this type of policy is public education.

We model public education as an insurance system that increases the income of the low talented children, at the expense of lowering the income of the more talented children. We show how and why a more progressive educational policy increases social mobility in equilibrium. The equilibrium level of social mobility depends on the costs and benefits of public education. This trade-off is resolved by two forces: (a) the balance between costly insurance and incentives to privately invest in children's human capital and (b) the political process that aggregates conflicting interests regarding the desired degree of social mobility.

A novel insight of our analysis is to show how political economy forces shape the equilibrium level of social mobility. Even if public education is relatively costless to provide for the average family, it may hurt the interests of the rich dynasties who, in a world of increased social mobility, are more likely to move down the income ladder. As a result, the maximum amount of mobility $(\beta=0)$ is not necessarily the equilibrium one, even when public insurance is relatively cheap to provide.

More generally, the model shows that existing differences in $\beta$ across countries are (at least in part) governed by all those political institutions that affect public education. Therefore, two societies with similar fundamentals (such as the degree of parental altruism, variability in market earnings, degree of biological and cultural transmission of family characteristics, labor market discrimination, asset market incompleteness etc.) may display very different degrees of intergenerational mobility depending on the identity of the politically decisive family.

In the last part of the paper, we use data on a cross section of countries for which reliable estimates of $\beta$ are available to test the predictions of the model. In general, we find that they are consistent with the empirical evidence. 
For example, our model predicts that in countries where rich dynasties are more politically active than poor dynasties, social spending for public education should be lower and therefore income mobility should be lower. We find that this appears to be the case in our sample. The difference in the probability of party affiliation between rich and poor appears to be strongly correlated with $\beta$. Such difference has five times larger predictive power than the rate of return to education, which is often considered as one of the most prominent determinants of mobility (Solon 1999, 2004; Corak 2006). While causality is obviously unclear, these empirical correlations are at least consistent with our model.

The rest of the paper is organized as follows. Section II discusses the related literature. In Section III we describe the model and examine its positive properties. In Section IV we derive the politico-economic determinants of social mobility and show their relation to the GBS regression. In Section V we present our empirical evidence. Section VI concludes. All omitted derivations are in Appendix A. Appendix B describes the data.

\section{RELATED LITERATURE}

The objective of our model is to derive the structural politico-economic parameters underlying the intergenerational elasticity of income. This coefficient - $\beta$ in Equation (1) - has been the main focus of the existing empirical literature: see among others Solon (1992); Zimmerman (1992); Björklund and Jäntti (1997); Mulligan (1997) and Solon (1999). Our model is also related to a more recent empirical strand of research that examines within-country trends in mobility and compares $\beta$ over time; see for instance Mazumder (2005, 2007); Lee and Solon (2006); and Aaronson and Mazumder (2008).

Most theoretical work in this area has focused on the role of the genetic transmission of ability, the incentives for parental investment, and the role of the asset market in explaining the intergenerational transmission of income. Our framework builds on the theoretical work of Becker and Tomes (1979), and on extensions of this work by Goldberger (1989); Mulligan (1997); and Solon (2004).

While some studies have highlighted the role of public policies as a determinant of social mobility, most existing studies take these policies as exogenous. Examples of papers that have argued that institutions may be important determinants of mobility, but take these institutions as exogenous include, among others, the original contribution of Becker and Tomes (1979); Glomm and Ravikumar (1992); Checchi, Ichino, and Rustichini (1999); Solon (1999, 2004); Davies, Zhang and Zeng (2005); Mayer and Lopoo (2005); and Hassler, Rodriguez Mora, and Zeira (2007).

In our setting, social mobility depends on public redistributive policies that we model as the outcome of a politico-economic equilibrium. In this sense, our model relates to the equilibrium models of Saint-Paul and Verdier (1993); Alesina and Rodrik (1994); and Persson and Tabellini (1994). These papers show how crosssectional inequality causes growth, through endogenous public policies. Benabou (1996) further develops this strand of literature and endogenizes the relationship between inequality, social mobility, redistribution and growth as a function of the incompleteness of the financial market. While our model abstracts from (physical) capital accumulation, it emphasizes the endogenous production of human capital (talent) as an intermediate input for the production of final income. Fernandez and Rogerson (1998) analyze a reform from a locally financed to a centralized educational system in a multicommunity model with endogenous choice of location. Relative to their paper, we instead focus on explaining cross country outcomes. In this case, migration becomes a less important determinant of social mobility and differences in political institutions become stronger determinants of social mobility. As in our paper, Bernasconi and Profeta (2007) endogenize institutions in a model with mobility and argue that the politically determined level of public education may reveal the true talent of the children and relax the mismatch of talents to occupations. Relative to this paper, our model includes both economic and political choices.

In a seminal paper, Piketty (1995) explains the emergence of permanent differences in attitudes toward redistribution. Benabou and $\mathrm{Ok}$ (2001) show how rational beliefs about one's relative position in the income ladder affect the equilibrium level of redistribution. These papers derive the implications of social mobility for redistributive policies, while we focus on the reverse channel. Specifically, we analyze how endogenously chosen public policies affect the intergenerational mobility.

It is important to note that because the direction of causation in our model differs from 
the one emphasized in the study of Benabou and Ok (2001), we obtain a different prediction for the relationship between mobility and redistribution in the United States and Europe. In their paper, more mobility is associated with less redistribution because voters who are below the mean oppose redistribution in the rational expectation of income gains in the future. This explanation is intuitive, but cross Atlantic evidence suggests that the United States is less mobile and less redistributive than continental Europe. ${ }^{1}$ In our paper, political economy forces that constrain the development of public education also lead to a lower degree of social mobility. Thus, our model predicts a positive correlation between social mobility and redistribution of income across countries.

\section{A SIMPLE MODEL OF THE} INTERGENERATIONAL TRANSMISSION OF INCOME

We first set up the model and derive the intergenerational transmission equation for income and talent. Then, we derive the first and second moments of income and talent distributions and discuss how these moments evolve in response to more progressive public policies.

\section{A. Setup of the Model}

We consider an infinite horizon overlapping generations economy populated by a measure one of dynasties, $i \in[0,1]$. In each period $t=$ $0,1,2, \ldots$ two generations are alive, fathers and sons. In each generation, earnings (which we also call "output" or "income" interchangeably) are produced according to the production function $Y_{i, t}=f\left(\mu_{t}, \Theta_{i, t}, U_{i, t}\right)$. The parameter $\mu_{t}$ represents the public policy; $\Theta_{i, t}$ is father's human capital or basic skill (e.g., IQ) which we call "talent"; and $U_{i, t}$ denotes a random and inelastic factor of production which represents "market luck." Specifically, we assume that the production function is given by:

$$
Y_{i, t}=\mu_{t}^{\alpha}\left(U_{i, t} \Theta_{i, t}\right)^{\mu_{t}}
$$

where $\mu_{t} \in(0,1]$ and $\alpha \geq 0$.

Figure 1 shows the production function graphically. Public policy and its effects are characterized by two parameters, $\mu_{t}$ and $\alpha$. The parameter $\mu_{t}$ characterizes the amount of redistribution in the economy. A lower $\mu_{t}$ implies a

1. See the evidence in Section V. See also Alesina and Glaeser (2004) for more on this point. more progressive public policy, but also more distortions. This is shown visually in the left panel of Figure 1, where for a given amount of talent and market luck, a lower $\mu_{t}$ is associated with less output for the talented or lucky families, but with more output for the less talented or unlucky families. The most natural example of the public policy represented by $\mu_{t}$ is public education. In Section $\mathrm{V}$ we offer evidence in line with this interpretation of $\mu_{t}{ }^{2}$ Henceforth, a lower $\mu_{t}$ is called a more progressive public policy or a more progressive educational system.

The parameter $\alpha$ characterizes the efficiency of public education. For a given $\mu_{t}$, a higher $\alpha$ implies that a smaller fraction of talents $\Theta_{i, t}$ gains from progressivity because the system creates disincentives for high talented agents. In the right panel of Figure 1, the area to the left of the intersection of the production function with the $45^{\circ}$ line measures the gains from progressivity. As $\alpha$ increases, this area becomes smaller relative to the area to the right of the intersection of the production function with the diagonal, which measures the efficiency costs of progressivity. ${ }^{3}$ Henceforth, a higher $\alpha$ denotes more distortions.

In each period $t$ the following events take place:

1. Fathers produce output $Y_{i, t}$ according to Equation (2), given the predetermined talent $\Theta_{i, t}$, market luck $U_{i, t}$ and public policy $\mu_{t}$.

2. Fathers choose the policy for their sons, $\mu_{t+1}$, according to the institution or political process $P$.

3. Sons are born with a random family endowment $V_{i, t+1}$. The random factor of production $U_{i, t+1}$ is realized.

4. Fathers observe $V_{i, t+1}$ and $U_{i, t+1}$ and choose investment $I_{i, t}$ to maximize the dynastic utility, given resources $Y_{i, t}$. Investment produces son's talent according to the production function $\Theta_{i, t+1}=g\left(I_{t}, h_{i} V_{i, t+1}\right)$.

5. Fathers die, sons become fathers and the process repeats ad infinitum.

For this section we treat $\mu$ as an exogenous parameter. In Section IV we endogenize it. Son

2. Pekkarinen, Uusitalo, and, Kerr (2008) show how the major Finnish educational reform in the 1970s decreased the intergenerational elasticity of income from 0.30 to 0.23 . Their finding is consistent with our interpretation of $\mu_{t}$.

3. We do not restrict $\Theta_{i, t}$ to be smaller than unity. If in some period $\Theta_{i, t} \leq 1$ for all families $i$, we can think the special case with $\alpha=0$ as a growth-enhancing reform that benefits every family, with the least talented families gaining relatively more. 
FIGURE 1

The Production Function $Y_{i, t}=\mu_{t}^{\alpha}\left(U_{i, t} \Theta_{i, t}\right)^{\mu_{t}}$

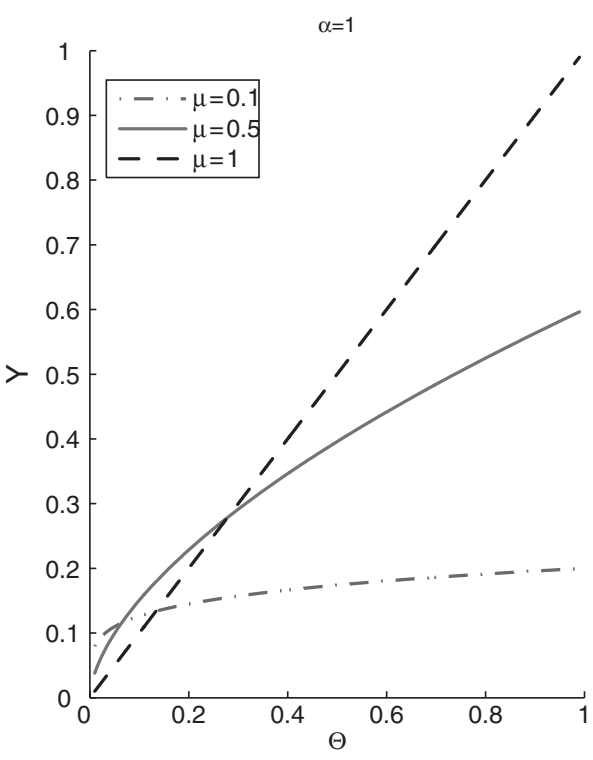

Note: Market luck is set to $U_{i, t}=1$.

$i$ is born with random family endowment $V_{i, t+1}$, which, following Becker and Tomes (1979), is assumed to follow a "Galtonian" AR(1) process:

$$
v_{i, t+1}=\left(1-\rho_{1}\right) \rho_{0}+\rho_{1} v_{i, t}+\epsilon_{i, t+1}
$$

where $v=\ln V$ (small caps denote $\operatorname{logs}$ of corresponding variables throughout the paper). For every dynasty $i, \epsilon_{i, t+1}$ is a white noise process with expected value $\mathbf{E}\left(\epsilon_{i, t}\right)=0$, variance $\operatorname{Var}\left(\epsilon_{i, t}\right)=\sigma_{v}^{2}$ and zero autocorrelations. We have $0 \leq \rho_{1}<1$ and therefore the logarithm of family endowment regresses toward the mean, has stationary expectation $\mathbf{E}\left(v_{i, t}\right)=$ $\rho_{0}$, and has stationary variance $\operatorname{Var}\left(v_{i, t}\right)=$ $\sigma_{v}^{2} /\left(1-\rho_{1}^{2}\right)$. The parameter $\rho_{1}$ characterizes the cultural or genetic inheritance of traits related to talent and income, and is assumed identical across families $i$.

A second random component is represented by market luck, $U_{i, t+1}$, whose logarithm is a white noise process, has variance $\sigma_{u}^{2}$, and is independent to $\epsilon_{i, t}$. The difference between $U_{i, t}$ and $\Theta_{i, t}$ is that the latter is an elastic factor of production. As a result, talent is affected by the inefficiencies associated with the policy $\mu$.

Fathers care about the quality of their children. They observe $V_{i, t+1}$ and $U_{i, t+1}$ and decide how to allocate their predetermined income $Y_{i, t}$

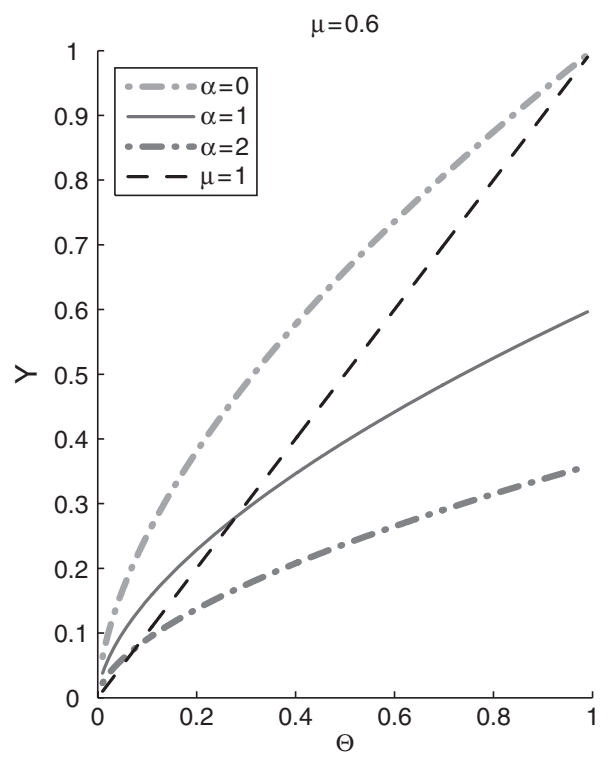

into consumption $C_{i, t}$ and investment $I_{i, t}$ in order to maximize the dynastic utility:

$$
\ln C_{i, t}+\frac{1}{\gamma} \ln Y_{i, t+1}
$$

subject to the budget constraint:

$$
C_{i, t}+I_{i, t}=Y_{i, t}
$$

where $Y_{i, t+1}$ is children's income. ${ }^{4}$ The parameter $\gamma>0$ captures the degree of parental altruism, with higher values denoting smaller altruism. Parental investment $I_{i, t}$ can be thought as an private educational input (e.g., tuition fees) that increases a child's talent.

Sons' talent is produced with the following production function:

$$
\Theta_{i, t+1}=\left(h_{i} V_{i, t+1}\right) I_{i, t}
$$

where $h_{i}$ is a family-specific time-invariant ability effect which allows dynasties to be ex ante heterogeneous. This heterogeneity captures long-run differences in market incomes, for instance due to labor market discrimination

4. We assume that fathers cannot borrow against their son's future income. See Loury (1981); Becker and Tomes (1986) and Mulligan (1997), for an analysis of the relationship between social mobility and borrowing constraints. See also Benabou (1996, 2000). 
against certain racial, ethnic, or religious groups. We assume that $h_{i}$ is distributed according to the density function $\phi_{h}$ with bounded support $\mathbf{H} \subset R_{++}$, and is orthogonal to the disturbances $\epsilon_{i, t+1}$ and $u_{i, t+1}$.

\section{B. The Transmission of Income Across Generations}

In this Section we restrict attention to steadystate public policies, that is we set $\mu_{t+1}=\mu_{t}=$ $\mu$ for all $t$. Under this assumption, income and talent are stochastic processes with well defined and easy to analyze unconditional stationary moments. We generalize our analysis in Section IV, where we endogenize the choice of $\mu$. Solving the problem in Equations (4)(5), using the production functions (2) and (6), and taking logs, we obtain the equation that describes the intergenerational transmission of income in family $i$ :

$$
y_{i, t+1}=\delta_{0, i}+\delta_{1} y_{i, t}+\delta_{2} v_{i, t+1}+\delta_{3} u_{i, t+1}
$$

where:

$$
\begin{aligned}
\delta_{0, i} & =\delta_{0}+\delta_{i} \\
\delta_{0} & =\mu \ln \left(\frac{\mu}{\mu+\gamma}\right)+\alpha \ln \mu \\
\delta_{i} & =\mu \ln h_{i} \\
\delta_{1} & =\mu \\
\delta_{2} & =\mu \\
\delta_{3} & =\mu
\end{aligned}
$$

The intercept $\delta_{0, i}$ can be decomposed into two parts. $\delta_{0}$ is a common effect across all dynasties $i$, and $\delta_{i}$ is the dynasty-specific timeinvariant effect due to $h_{i}$. Our autoregressive coefficient, $\delta_{1}$, is different from the one described by Becker and Tomes (1979) because we assume multiplicative (in levels) production functions for output and talent. ${ }^{5}$ While the previous literature has focused on the role of private incentives for the intergenerational mechanism, our $\delta_{1}$ coefficient emphasizes instead the role of public policies. Specifically, the novel element of our model is that the slope $\delta_{1}$ is collectively

5. Goldberger (1989) explains in detail the difference between the additive production function (as in the Becker and Tomes model) and the multiplicative production function. We also note that in our specific Cobb-Douglas environment, the degree of parental altruism $(\gamma)$ does not enter into the intergenerational transmission equation directly, that is, for given policy $\mu$ (see Solon 2004, for a similar result). decided by the fathers of each dynasty. Therefore, our mechanism maps collective action outcomes to equilibrium levels of intergenerational transmission of income. In the Appendix we present the intergenerational transmission of talent.

\section{The Trade-Off Between Equity and Efficiency}

Expectations. From Equation (7) we take the unconditional, stationary expectation of income ("long-run income") for family $i$ :

$$
\mathbf{E}\left(y_{i, t+1} \mid h_{i}\right)=\frac{\mu\left[\rho_{0}+\ln h_{i}+\ln \left(\frac{\mu}{\mu+\gamma}\right)\right]}{+\alpha \ln \mu}
$$

for all $t$. In Equation (14), the expectation is conditioned only on $h_{i}$ to denote the dependency of long-run income on long-run family ability $h_{i}$. There are four ways through which the public policy $\mu$ affects long-run income.

1. Distortions in Private Investment: This is captured by the $\ln \left(\frac{\mu}{\mu+\gamma}\right)$ term. When public policy becomes more progressive (lower $\mu$ ), the marginal propensity to invest in human capital, $\mu /(\mu+\gamma)$, is lower and as a result the long-run level of income tends to decline. This effect is identical for every dynasty $i$.

2. Direct Distortions in Output: This effect is shown in the $\alpha \ln \mu$ term, and is associated with the shifter $\mu^{\alpha}$ in the production function for income in Equation (2). The effect of $\mu$ on output is more adverse when the parameter $\alpha$ increases.

3. Social Insurance or Benefits of Public Education: The $\mu$ term that multiplies the bracket in the numerator of Equation (14) captures the exponent of the term $\Theta^{\mu}$ in Equation (2). For low ability dynasties (low $h_{i}$ ), a more progressive public educational system increases long-run income. The opposite happens for sufficiently high ability families. The intuition is shown in Figure 1.

4. Intertemporal Insurance or Social Mobility: This effect is given by the denominator $1-\mu$ and is associated with the slope $\delta_{1}$ of the intergenerational transmission of income in Equation (7). For sufficiently low ability dynasties $\left(\right.$ low $h_{i}$ ), the numerator is negative and the prospect of upward mobility (lower $\mu$ ) increases long-run income. For high ability dynasties, the 
numerator is positive and increased mobility decreases their long-run income.

We can write father $i$ 's conditional (on the state of the system) expectation for son's income as the sum of the long-run level of income in Equation (14) and the transitory deviation of current income and current family endowment from their long-run levels:

$$
\begin{aligned}
\mathbf{E}_{t}\left(y_{i, t+1} \mid h_{i}\right)= & \mathbf{E}\left(y_{i, t+1} \mid h_{i}\right) \\
& +\mu\left(y_{i, t}-\mathbf{E}\left(y_{i, t+1} \mid h_{i}\right)\right) \\
& +\mu \rho_{1}\left(v_{i, t}-\rho_{0}\right)
\end{aligned}
$$

where the time subscript in the left hand side denotes conditioning on the information set as of period $t$ (which is summarized by father's income, $y_{i, t}$, and family endowment, $v_{i, t}$ ). As we show in Section IV.A, fathers take into account how progressivity affects this conditional expectation when voting for $\mu$.

This analysis highlights two important points. First, there is a trade-off between equity and efficiency. Second, there is political conflict over the equilibrium level of social mobility. In particular, as we discuss more formally in Section IV.B, fathers with higher ability $h_{i}$ or with favorable shocks in their market activity, $u_{i, t}$, or in their family endowment, $v_{i, t}$, prefer less progressive policies. It is this heterogeneous effect of $\mu$ on dynastic welfare that makes the political economy aspect of the model interesting and supports our argument that politico-economic determinants may be significantly associated with mobility outcomes.

Variances. To understand the implication of our model for inequality, we first consider the stationary, unconditional variability that a given dynasty $h_{i}$ faces in its income process. From Equation (7) this is:

$$
\begin{aligned}
\operatorname{Var}\left(y_{i, t+1} \mid h_{i}\right)= & \frac{\mu^{2}}{1-\mu^{2}} \frac{1+\rho_{1} \mu}{1-\rho_{1} \mu} \frac{\sigma_{v}^{2}}{1-\rho_{1}^{2}} \\
& +\frac{\mu^{2}}{1-\mu^{2}} \sigma_{u}^{2}
\end{aligned}
$$

Inequality across generations occurs because the disturbances $\epsilon_{i, t+1}$ and $u_{i, t+1}$ have different realizations across time for a given family $i$. From inspection of Equation (16), we see that a more progressive system (lower $\mu$ ) reduces the variability of income. In addition, it lowers the fraction of variability attributed to family luck $v_{i, t+1}$. Intuitively, market luck $u_{i, t+1}$ matters only for the final production of income, while family luck $v_{i, t+1}$ affects both the production of talent directly, and the production of final output indirectly (through talent). As a result, more progressive public policies reduce the relative importance of the latter in the intergenerational variance of income.

If all families were identical, then the variance that families face across generations in Equation (16) coincides with the stationary inequality in the cross section of families. More in general, with heterogeneous families, the ex post or cross-sectional variance of income can be decomposed in two parts: 6

$$
\begin{aligned}
\operatorname{Var}\left(y_{i, t+1}\right)= & \operatorname{Var}\left(y_{i, t+1} \mid h_{i}\right) \\
& +\operatorname{Var}\left(\mathbf{E}\left(y_{i, t+1} \mid h_{i}\right)\right)
\end{aligned}
$$

The second term in Equation (17) represents the variance "under the veil of ignorance," which from Equation (14) equals:

$$
\operatorname{Var}\left(\mathbf{E}\left(y_{i, t+1} \mid h_{i}\right)\right)=\frac{\mu^{2} \operatorname{Var}\left(\ln h_{i}\right)}{(1-\mu)^{2}}
$$

To summarize, in Equation (17) the stationary total inequality in the cross section of families is decomposed into the dynastic variability in the process for income-common to all families $i$-and the inequality that arises because heterogeneous families have different levels of long-run income. It is immediate to see that a more progressive educational system reduces all inequalities. In the Appendix we also discuss the variance of talent.

Covariances. Consider now the intergenerational correlation of income. This summary statistic is what the literature calls social mobility, inequality across generations or "equality of opportunity." Conditioning on $h_{i}$, we distinguish the intergenerational correlation of income within family, $\operatorname{Corr}\left(y_{i, t+1}, y_{i, t} \mid h_{i}\right)$, from the correlation we may observe in the data when families are heterogeneous, $\operatorname{Corr}\left(y_{i, t+1}, y_{i, t}\right)$. The latter is discussed in Section IV.C in relation to the GBS regression. Consider the time

6. In Equation (16) the variance is not indexed by $i$ and as a result $\mathbf{E}_{h_{i}}\left(\operatorname{Var}\left(y_{i, t+1} \mid h_{i}\right)\right)=\operatorname{Var}\left(y_{i, t+1} \mid h_{i}\right)$. The variance of income is common to all families $i$ because $h_{i}$ enters multiplicatively into the production of talent (6). The same comment applies for the intergenerational correlation of incomes below. In a more general version of our model, we could allow for heterogeneity in the returns to investment (e.g., with a production function of the form: $\left.\Theta_{i, t}=\left(h_{i} V_{i, t+1}\right) I_{i, t}^{\xi_{i}}\right)$. Under this specification the slope of the regression $\left(\delta_{1}\right)$ in Equation (7) depends on $i$. 
series of output and talent for some family $i$ with time-invariant ability level $h_{i}$. Given that we are in a stationary state with $\operatorname{Var}\left(y_{i, t+1} \mid h_{i}\right)=$ $\operatorname{Var}\left(y_{i, t} \mid h_{i}\right)$, we can derive the dynastic intergenerational correlation of income:

$$
\begin{array}{r}
\operatorname{Corr}\left(y_{i, t+1}, y_{i, t} \mid h_{i}\right)=\frac{\operatorname{Cov}\left(y_{i, t+1}, y_{i, t} \mid h_{i}\right)}{\operatorname{Var}\left(y_{i, t} \mid h_{i}\right)} \\
=\frac{\left(\mu+\rho_{1}\right) \sigma_{v}^{2}+\mu\left(1-\rho_{1} \mu\right)\left(1-\rho_{1}^{2}\right) \sigma_{u}^{2}}{\left(1+\rho_{1} \mu\right) \sigma_{v}^{2}+\left(1-\rho_{1} \mu\right)\left(1-\rho_{1}^{2}\right) \sigma_{u}^{2}}
\end{array}
$$

For talent, the correlation $\operatorname{Corr}\left(\theta_{i, t+1}, \theta_{i, t} \mid h_{i}\right)$ is given in Appendix A.

\section{Summary}

In Proposition 1 we summarize how a more progressive public policy (lower $\mu$ ) affects the moments of income and talent.

\section{PROPOSITION 1. Effects of Progressivity on}

Income and Talent: In any stationary state, with a time-invariant public policy $0<\mu_{t+1}=\mu_{t}=$ $\mu \leq 1$ we have:

1. A more progressive system (lower $\mu$ ) decreases/increases long-run income and talent for sufficiently high/low $h_{i}$ families. A more progressive system favors families with temporarily low output, $y_{i, t}<\boldsymbol{E}\left(y_{i, t+1} \mid h_{i}\right)$, and it favors families with temporarily low family endowment, $v_{i, t}<\rho_{0}$.

2. The dynastic variance of income, Var $\left(y_{i, t+1} \mid h_{i}\right)$, and the dynastic variance of talent, $\operatorname{Var}\left(\theta_{i, t+1} \mid h_{i}\right)$, are increasing in $\mu . \operatorname{Var}\left(y_{i, t+1} \mid h_{i}\right) /$ $\operatorname{Var}\left(\theta_{i, t+1} \mid h_{i}\right)$, that is, the intra-family ratio of intergenerational inequalities, is bounded above by 1 , and is increasing in $\mu$.

3. The cross-sectional inequality of income $\operatorname{Var}\left(y_{i, t+1}\right)$ and the cross-sectional inequality of talent $\operatorname{Var}\left(\theta_{i, t+1}\right)$ increase in $\mu$. Their ratio is bounded above by 1 and also increases in $\mu$.

4. The dynastic intergenerational correlation of income Corr $\left(y_{i, t+1}, y_{i, t} \mid h_{i}\right)$ is increasing in $\mu$. The ratio $\operatorname{Corr}\left(y_{i, t+1}, y_{i, t} \mid h_{i}\right) / \operatorname{Corr}\left(\theta_{i, t+1}\right.$, $\left.\theta_{i, t} \mid h_{i}\right)$ is smaller than 1 , and increases in $\mu$.

Proposition 1 shows how a more progressive public policy decreases the dynastic and cross-sectional inequalities of income and talent, and also decreases the within-dynasty intergenerational correlation of income. These two predictions are consistent with the general equilibrium effects of educational subsidies as derived recently by Hassler, Rodriguez Mora, and Zeira (2007). They also tend to imply a positive comovement of the cross-sectional and the intergenerational inequality, as discussed by Solon (2004). Finally, our model predicts that in a society with no public policy $(\mu=1)$, the ratio of variances and intergenerational correlations of income over talent take their maximum value (unity). As public policy becomes more progressive these ratios decrease. Intuitively, when the progressivity of public education increases, a given amount of variation in the production of talent across time or across families matters less for final earnings in the market. $^{7}$ In Section V we offer some evidence in line with this prediction.

\section{THE POLITICAL ECONOMY OF SOCIAL MOBILITY}

First, we define the politico-economic equilibrium. Then, we derive the equilibrium choice of the public policy $\mu$ in terms of deeper political, economic, cultural, and genetic parameters. Finally, we show the relationship between the equilibrium level of $\mu$ and the slope of the GBS regression, $\beta$.

\section{A. Politico-Economic Equilibrium}

In period $t$, father $i$ observes and takes as given the realization of last period's output, $y_{i, t}$, and endowment, $v_{i, t}$. However, fathers do not know the realization of children's endowment $v_{i, t+1}$ and market luck $u_{i, t+1}$ before they vote for $\mu_{t+1}$ and they need to form rational expectations. Father $i$ 's preferences over public policies $\mu_{t+1}$ are ordered according to the conditional expectation of Equation (4):

$$
\begin{aligned}
W\left(\mu_{t+1} ;\right. & \left.h_{i}, y_{i, t}, v_{i, t}, s\right) \\
& =\ln C_{i, t}+\frac{1}{\gamma} \mathbf{E}_{t}\left(y_{i, t+1} \mid h_{i}\right)
\end{aligned}
$$

where $s$ is the vector of structural parameters, and the conditional expectation, $\mathbf{E}_{t}\left(y_{i, t+1} \mid h_{i}\right)$, is given by Equation (15). $C_{i, t}$ is the optimal level of consumption:

$$
C_{i, t}=\frac{\gamma}{\mu_{t+1}+\gamma} Y_{i, t}
$$

which is a function of the public policy. Note that we reinstate the time subscript in $\mu$.

7. This result reflects the difference between the coefficients $\delta_{2}$ and $\lambda_{2}$ (or $\delta_{i}$ and $\lambda_{i}$ ) in the two intergenerational transmission equations. See Appendix for the details. 
An important simplification for deriving the equilibrium in our model is that sons are born after fathers have chosen the public policy $\mu_{t+1}$. As a result, sons do not affect the choice of $\mu$. Under this assumption, preferences of fathers over current policies are independent of future policies, and there is no need to explicitly consider dynasties' expectations about future policy outcomes. ${ }^{8}$ This assumption is intuitive in the context of intergenerational mobility. As we discuss in Section $\mathrm{V}$ in a cross section of OECD countries, it is public spending on educationrather than other forms of government activitythat strongly correlates with social mobility. Since public education is regarded as highly redistributive at the primary level, that is, before sons' political rights are extended, our assumption captures this realistic feature of the intergenerational transmission.

The policy that maximizes Equation (20) is called the "most preferred policy for dynasty $i$ ":

$$
\begin{aligned}
\mu_{i, t+1} & =\mu\left(h_{i}, y_{i, t}, v_{i, t} ; s\right) \\
& =\arg \max _{\mu} W\left(\mu ; h_{i}, y_{i, t}, v_{i, t}, s\right)
\end{aligned}
$$

The most preferred policy for every father reflects various trade-offs. First, it reflects the four channels that affect the long-run value of income in Section III.C. In addition, transitory deviations from long-run income and transitory deviations from long-run family endowment also affect the most preferred policy, as shown in Equation (15). Finally, public policy allocates resources intertemporally and creates a trade-off across generations. The consumptioninvestment ratio for every father is $\gamma / \mu_{t+1}$. A less progressive system (higher $\mu_{t+1}$ ) distorts less the incentive of parents to privately invest in their children talent and therefore when $\mu_{t+1}$ decreases parents transfer more resources to the next generation.

8. That is, the indirect utility $W$ in Equation (20) depends only on the current choice variable, $\mu_{t+1}$, and not on future public policies, $\mu_{t+2}, \ldots$. As a result, we do not have to consider the policy-fixed point problem that arises when current policies depend on expectations of future policies but also affect future policies through the optimal consumption and investment choices and the resulting intergenerational transmission of income and talent. Our setup resembles the equilibrium in the models of Persson and Tabellini (1994); Benabou (1996); and Fernandez and Rogerson (1998), with "one period-ahead commitment to policy." Krusell, Quadrini, and Rios-Rull (1997) show how to formulate and numerically solve for time-consistent politico-economic equilibria in a general class of models. Hassler et al. (2003) solve closed-form the Markov perfect equilibrium in a nontrivial dynamic voting game under the assumption of risk neutrality.
To solve the model we define a relevant family-specific summary of the system which we call "income potential," $Q_{i, t}$. Income potential therefore summarizes the history of all relevant market and family shocks. Our functional form assumptions-log preferences and multiplicative production functions-imply that income potential for family $i$ at time $t$ is the logsum of three terms: life-long ability level $\ln h_{i}$, current log income, $y_{i, t}$, plus a term proportional to $\log$ family endowment, $v_{i, t}$.

$$
Q_{i, t}=\ln h_{i}+y_{i, t}+\rho_{1} v_{i, t}
$$

\section{PROPOSITION 2. Preferences over Public Policy:}

1. Induced preferences over $\mu_{i, t+1}$ as described by $W($.$) in Equation (20) are single-$ peaked if (but not only if) $\alpha>1$ for any $Q_{i, t}$.

2. The most preferred policy $\mu_{i, t+1}$ is strictly increasing in $Q_{i, t}$.

The first part of the Proposition establishes a sufficient condition for the indirect utility $W$ to be single-peaked. The second part shows that families with higher income potential prefer less progressive public policies. Families with high income potential may be families from advantaged groups (high $h_{i}$ ) or families that face favorable economic $\left(y_{i, t}>\mathbf{E}\left(y_{i, t+1} \mid h_{i}\right)\right)$ or cultural $\left(v_{i, t}>\rho_{0}\right)$ shocks. Therefore, in our model families from disadvantaged social groups (low $h_{i}$ ) may still prefer less progressive public policies, if their last generations experienced good luck in the market or in the production of talent.

Because transitory shocks affect preferences for public policies, in general the equilibrium policy will not be time invariant, as assumed for simplicity in Section III. The easiest but most restrictive way to proceed is to assume a precommitment institution in which the initial generation of fathers observe $\left\{y_{i, 0}, v_{i, 0}, h_{i}\right\}$ and choose once and for all a time-invariant system $\mu$, which by assumption remains active in all future periods. A second possibility is to consider the stochastic steady state of the model, in which the distribution of income potentials in the population is stationary. In this case, the optimal $\mu$ remains constant in time, but the identity of the decisive family is allowed to vary, since in the steady-state families are hit by different market and family shocks. Under both these cases, the analysis for the long-run moments in Section III applies, and the timeinvariant coefficients for the stochastic processes 
are given by the optimal stationary $\mu$. Finally, we can apply our comparative statics to the most general case, when the dynastic variance and the public policy depend on calendar time along the transitional dynamics in a period-by-period decision making process. Under this setting, the equilibrium public policy (yet to be defined) will in general depend on the current state $Q_{i, t}$ of the decisive father. ${ }^{9}$

Let the distribution of income potential in the cross section of dynasties at time $t$ be $\Phi_{t}(Q)=\int_{Q_{l, t}}^{Q} \phi_{t}(z) d z$. We define the political institution in terms of the equilibrium outcome that it implies.

DEFINITION 1. Institution P: An institution $P$ results in the public policy $\mu_{t+1}^{e}$ mostly preferred by the dynasty in the 100 pth percentile of the income potential distribution $\Phi_{t}$, that is, the family with an income potential such that $p=\Phi_{t}\left(Q_{i, t}\right)$. We denote the decisive dynasty as $Q_{p, t}$.

Our definition encompasses some commonly used institutions, both in the optimal policy and in the political economy literature. Let the average income potential be $\bar{Q}_{t}=\int_{\mathbf{Q}_{t}} z d \Phi_{t}(z)$. Then if $p=\Phi_{t}\left(\bar{Q}_{t}\right)$, one obtains the utilitarian social rule that maximizes the welfare of the average father or the welfare "behind the veil of ignorance" for $Q_{i}$ :

$$
\max _{\mu} \int_{\mathbf{Q}_{t}} W(\mu, z ; s) d \Phi_{t}(z)
$$

In reality, however, public policies are determined by the aggregation of known, conflicting

9. As a result, income and talent become regime switching stochastic processes, that is, with time varying coefficients. One interesting and realistic case occurs if there is an adjustment cost associated with an educational reform that aims to switch $\mu$. In this case, the process for output would be a threshold $\operatorname{ARMA}(2,1)$ process, where the thresholds are defined by the distribution of $Q_{i, t}$ in the cross section of families. For instance, suppose that the fixed costs of expanding the public schooling infrastructure are too prohibitive and therefore $\mu$ can take only two values: $0<\mu_{l}<\mu_{h}<1$. Assuming that in period $t-1$, $\mu_{t}=\mu_{h}$ was the optimal grandfather's choice, a majority of fathers support a switch of regime to $\mu_{t+1}=\mu_{l}$, if $\int_{Q_{l, t}}^{K} \phi_{t}(z) d z>1 / 2$ where $K=\ln \frac{\gamma+\mu_{l}}{\gamma+\mu_{h}}\left(\frac{\gamma}{\mu_{l}-\mu_{h}}-1\right)-$ $\ln \frac{\mu_{h}}{\mu_{l}}+\frac{\alpha}{\mu_{l}-\mu_{h}} \ln \frac{\mu_{h}}{\mu_{l}}-\rho_{0}\left(1-\rho_{1}\right)$ is a constant, $\phi_{t}$ denotes the probability distribution of income potential in the cross section of dynasties as of the beginning of period $t$ and $Q_{l, t}$ is the lowest realized income potential. We index the distribution by $t$ to show the possible dependency on $\mu_{t}$ and hence on calendar time. Under this setting, the expectations, variances, and intergenerational correlations derived in Section III hold within each educational regime. political interests. The leading choice in the political economy literature is the one person, one vote democratic institution. If $\alpha>1$, then by Proposition 2 induced preferences over policies are single-peaked. As a result, the father with the median most preferred policy is the decisive voter. By the second part of the same Proposition, this is the father with the median income potential, $Q_{50, t}$. Note that this formulation allows both the identity and the income or the family endowment of the decisive father to vary over time. Since the median father's vote is decisive, it follows that $p=1 / 2$ is the unique equilibrium outcome of the pure majority rule game (i.e., the Condorcet winner).

More in general, we can allow for $p>$ $1 / 2$, capturing campaign contributions or more active political participation of the rich fathers. Alternatively, a higher $p$ may parameterize the ideologically diverse preferences for parties of the poor fathers, as in the probabilistic voting model. If $p<1 / 2$, then social preferences are averse to inequality and can be thought to internalize the ex ante variance given in Equation (18). From a political economy point of view, a lower $p$ may capture the bargaining power of socialist parties or labor organizations in unionized economies. In the limit, $p=0$ leads to the "Rawlsian institution" that maximizes the welfare of the least well-off dynasty. Henceforth, we parameterize political preferences with $p$. In Section V we show how to measure this key parameter in the data.

\section{B. Politico-Economic Determinants of Social Mobility}

Given this definition, the properties of the equilibrium level of the public policy, $\mu_{t+1}^{e}$, are given in the following Proposition.

PROPOSITION 3. Equilibrium Public Policy: The equilibrium policy $\mu_{t+1}^{e}$ is increasing both in $\alpha$ and in $p$. It increases in $h_{p}, y_{p, t}, v_{p, t}$ and in $\rho_{0}$, it decreases in $\gamma$, and it does not depend on $\sigma_{v}^{2}$ and $\sigma_{u}^{2}$. It increases in $\rho_{1}$ if and only if $v_{i, p}-\rho_{0}>0$.

This Proposition shows how public education becomes less progressive (higher $\mu_{t+1}$ ) when output costs $\alpha$ increase, but more progressive as the position of the decisive dynasty in the income potential distribution $p$ decreases. Our result shows that, as long as optimally chosen public policies have the potential to affect intergenerational mobility (which in our model is 
shown in Section IV.C), there is no reason to expect that a collective action of fathers transmits a perfectly mobile society to their sons $\left(\mu^{e}=\beta=0\right)$. It is important to note that for the refusal of this proposition, one would need to show both that the costs of progressive public policies are negligible and that institutions favor the low ability families. This is an interesting point, because empirically it may be difficult to find evidence for the magnitude of $\alpha$ or in reality some public reforms may entail small efficiency costs (Lindert 2004). On the other hand, a recent strand of research in political economy points out that various politico-economic outcomes can be simply explained by the fact that rich families have a larger "say" in the political equilibrium, that is, that the political system is wealth-biased (Benabou 1996; Campante 2007; Alesina and Giuliano 2009; Karabarbounis 2010).

What is the novelty of our results? Most of the existing literature following the initial Becker and Tomes (1979) contribution has attributed to the reduced-form coefficient in Equation (1) a specific meaning for social mobility, namely that equality of opportunity is desirable. ${ }^{10}$ If equality of opportunity is however costly for private incentives, more of it is not necessarily desirable. ${ }^{11}$ Relative to these views, our model emphasizes - in addition to standard incentive costs-political economy constraints that may further limit or enhance the extent of social mobility. For instance, in our model perfect social mobility may be optimal under

10. Becker and Tomes (1979; abstract and page 1182) argue that

"Intergenerational mobility measures the effect of a family on the well-being of its children."

(emphasis added). Another influential contribution is that of Mulligan (1997, page 25), who in defining social mobility notes that

"The degree of intergenerational mobility is [...] an index of the degree of 'equality of opportunity'. Equality of opportunity is often seen as desirable because, with little correlation between the incomes of parents and children, children from rich families do not enjoy much of a 'head start' on children from poor families."

The same presumption may be implied by the introductory paragraph in the study of Solon (1999).

11. Piketty (2000) and Corak (2006) make this point. In an influential paper, Atkeson and Lucas (1992) have shown the optimality of zero mobility. Recently, Phelan (2006) and Farhi and Werning (2007) challenge this result based on the social discount rate exceeding the private one. a utilitarian institution (if $\alpha$ is very small), but not politically sustainable if rich families and business interests restrict the development of the welfare state and the provision of public education (i.e., if $p$ is sufficiently high). To put it differently, two societies with similar dynastic fundamentals may display very different degrees of intergenerational mobility depending on which is the decisive dynasty selected by the existing political institutions.

The politico-economic trade-off behind our model can be conceptualized by a decline in the position of the decisive voter $p$. Societies in which families with lower income potential have a larger "say" for the equilibrium outcome, choose more progressive systems, expect higher mobility and lower inequality. However, progressivity results in a lower long-run level of income for sufficiently high ability families, and may even lower average income. ${ }^{12}$ In our model, if the distribution of income potential $\phi_{t}$ is right skewed $\left(Q_{50}<\bar{Q}\right)$ - perhaps because the ability distribution $\phi_{h}$ is skewed-then a majority voting of fathers chooses a more progressive public policy relative to the utilitarian optimum. Holding average income potential $\bar{Q}$ constant, an increase in the (right) skewness of the distribution of income potentials, leads the majority of fathers to demand more progressive policies and higher social mobility.

Interestingly, the effects of a higher ex ante inequality in abilities, $\operatorname{Var}(\ln h)$, due for instance to market discrimination against ethnically or racially diverse groups, depend on the political process $p$. If $p$ is low, then higher $\operatorname{Var}(\ln h)$ could be associated with more skewness and hence a poorer decisive voter which results in more progressive policies. On the other hand, if de facto political power is ultimately related to income potential and hence $p$ is relatively high, a higher ex ante variability could be associated with more powerful elites, less progressivity and lower social mobility. In Section V we offer some suggestive evidence in favor of the second effect. In the Appendix we discuss in more detail the intuition behind the other comparative statics of our model.

12. We have not explicitly considered the growthenhancing effects of public education. However, if average ability $\bar{h}$ is sufficiently low, then in the steady state the stationary average income in the cross section of the dynasties, $\int_{\mathbf{H}} \mathbf{E}\left(y_{i, t+1} \mid h\right) d \Phi_{h}(h)$, is decreasing in $\mu$, and the progressivity increases long-run income, which implicitly may be capturing this realistic feature of public education. 


\section{Structural Politico-Economic Interpretation of the Galton-Becker-Solon (GBS) Regression}

Our theoretical framework offers a structural interpretation for the log-linear intergenerational earnings model which is estimated in the empirical literature cited in Section II. The literature typically focuses on the GBS regression:

$$
y_{i, t+1}=a+\beta y_{i, t}+\varepsilon_{i}
$$

where $y_{t+1}$ and $y_{t}$ denote son's and father's lifelong log earnings in the population. Previous models have recognized that $\beta$ is a function of genetic and cultural inheritance, altruism, technological parameters and the structure of the asset market. However, we show that this coefficient also depends on political economy variables which determine the institutions that a generation puts in place to insure its offspring from adverse shocks.

PROPOSITION 4. Population Slope of the GBS Regression: The slope in the population regression of son's on father's income, $\beta$, also known as the intergenerational elasticity of income is given as follows. ${ }^{13}$

1. If the economy is in a stationary state with $\mu_{t+1}^{e}=\mu_{t}^{e}=\mu^{e}$, then the intergenerational elasticity equals the intergenerational correlation of incomes and is given by:

$$
\begin{aligned}
\beta & =\operatorname{Corr}\left(y_{i, t+1}, y_{i, t}\right) \\
& =\mu^{e}\left(1+\frac{\frac{\rho_{1} \mu^{e}}{\left(1-\rho_{1}^{2}\right)\left(1-\rho_{1} \mu^{e}\right)} \sigma_{v}^{2}+\frac{\mu^{e}}{1-\mu^{e}} \operatorname{Var}\left(\ln h_{i}\right)}{\operatorname{Var}\left(y_{i, t} ; \mu^{e}\right)}\right)
\end{aligned}
$$

where the variance in the denominator refers to the cross sectional variance in Equation (17) and $\mu^{e}$ is the equilibrium public policy defined in Proposition 3. The intergenerational elasticity $\beta$ increases in $\mu^{e}$ and in $p$.

2. If the economy is for a long time in the steady-state $\mu_{t}^{e}=\mu_{t-1}^{e}=\ldots$, but in $t+1$ an unexpected structural break in the political institution $p$ happens, then the intergenerational elasticity is given by:

$$
\beta_{t+1}=\mu_{t+1}^{e}\left(1+\frac{\frac{\rho_{1} \mu_{t}^{e} \sigma_{v}^{2}}{\left(1-\rho_{1}^{2}\right)\left(1-\rho_{1} \mu_{t}^{e}\right)}+\frac{\mu_{t}^{e}}{1-\mu_{t}^{e}} \operatorname{Var}\left(\ln h_{i}\right)}{\operatorname{Var}\left(y_{i, t} ; \mu_{t}^{e}\right)}\right)
$$

13. Note that in both cases $\beta$ is expressed only as a function of the deeper parameters of the model.
In this case $\beta_{t+1} / \beta_{t}=\mu_{t+1}^{e} / \mu_{t}^{e}$ and the ratio is increasing in $p_{t+1} / p_{t}$.

The first part of the proposition refers to the special case in which the economy is in a steady state with constant intergenerational mobility (the coefficient $\beta$ ) and cross-sectional variances. The second part considers instead the case in which a political shock at time $t$ determines a change of the decisive dynasty such that intergenerational mobility changes with respect to previous periods $\left(\beta_{t+1} \neq \beta_{t-i}\right.$ for $\left.i \geq 0\right)$ and cross-sectional income variances may differ across generations. In principle, analogous formulas can be obtained for other shocks affecting the intergenerational elasticity of incomes and cross-sectional variances, but given the focus of this paper here we study the case of a political shock.

Under the assumption that the advanced economies for which an estimate of $\beta$ is available are essentially characterized by a fairly similar set of economic and biological fundamentals, differences in the estimated $\beta$ for these countries should correlate with differences in the dynasty that has decisive power in the political process. To put it differently, if economic and biological fundamentals are more similar than political equilibria across these advanced economies, we should observe more mobility in countries in which the position of the decisive dynasty is lower in the hierarchy of dynastic income potentials. The empirical exercise in the next section should be interpreted as a suggestive assessment of the extent to which political economy variables that proxy for the decisive dynasty capture the cross-country variation in $\beta$.

However, Equations (26) and (27) emphasize also other more traditional determinants that might explain the cross-country variability in $\beta$. For example, in steady state and for given decisive dynasty, social mobility increases $(\beta$ decreases) with market luck variability (higher $\sigma_{u}^{2}$ ), and decreases with ex ante heterogeneity (higher $\left.\operatorname{Var}\left(\ln h_{i}\right)\right)$. It decreases with output costs (higher $\alpha$ ), with the ability of the decisive family (higher $Q_{p}$ ), with the long-run family endowment (higher $\rho_{0}$ ) and with the degree of altruism (higher $\gamma$ ). Greater market variability increases cross-sectional inequality and makes the position of children highly uncertain, thereby increasing social mobility. For the same reason, the comparative static with respect to $\sigma_{v}^{2}$ and $\rho_{1}$ is theoretically ambiguous. $\alpha, p, h_{p}, \rho_{0}$, and $\gamma$ affect social mobility indirectly, through 
the equilibrium level of $\mu$ (see Appendix for these comparative statics). Finally, note that our model predicts that ex ante heterogeneity $\operatorname{Var}\left(\ln h_{i}\right)$ affects positively $\beta$ only conditional on $\mu$. Higher ex ante heterogeneity may operate also indirectly through public policy, and it may increase (if it is associated with smaller $p$ ) or decrease (under higher $p$ ) social mobility.

\section{EMPIRICAL EVIDENCE ON THE POLITICO-ECONOMIC DETERMINANTS OF MOBILITY}

In this section we turn to the empirical evidence on the predictions of the model. Specifically, we present evidence on the relationship between political variables that our model indicates as important determinants of social mobility and observed measures of mobility across countries or within a country over time. We stress that this evidence needs to be interpreted only as suggestive and descriptive. The number of countries for which we have data is limited, and the available data are not sufficiently informative to identify causal relationships. Nevertheless, the evidence is generally consistent with the predictions of our model and in particular, it supports a positive cross-country and withincountry correlation between proxies for $p$ and estimates of $\beta$.

We consider first an interesting case study which represents a salient example of a political shock as described in Equation (27). Over the past few decades, the United Kingdom has experienced a tremendous decline in social mobility. In particular, Blanden, Gregg and Macmillan (2007) document a 50\% decline in social mobility between the 1958 and the 1970 cohorts. Such decline has generated widespread concern among the public and prompted the government in 2009 to issue a White Book that addresses the causes and implications of the decline in mobility. Blanden, Gregg and, Macmillan (2007) argue that the main cause of the decline is represented by changes in educational attainment of different income groups.

Their evidence is consistent with our model. However, our model goes further and indicates that educational policies are likely to be an endogenous outcome. According to our framework, the ultimate determinant of the decline in social mobility should be a change in societal preferences for redistribution. Indeed, this prediction is consistent with the sharp change in political preferences which led Margaret
Thatcher to become Prime Minister in 1979. The Thatcher revolution was caused by a clear move toward the right by the UK electorate, as indicated by the fact that public expenditure for education fell, the power of the unions declined, regressive value added taxes (VAT) increased, and more progressive corporate and income taxes declined. ${ }^{14}$

Turning to cross-country evidence, credible estimates of $\beta$ are available only for a limited number of countries. We use estimates from Corak's (2006) meta-analysis conducted for nine OECD countries and complement these with three more observations. In the Appendix we discuss more in detail the construction of our dataset and the sources. ${ }^{15}$

In Figure 2, the vertical axis shows estimates of $\beta$ for a cross section of advanced democratic OECD countries. Consistent with what has long been documented in the existing literature on mobility, the United Kingdom, the United States, and France are the least mobile, while Northern European countries appear the most mobile. Canada is the most mobile AngloSaxon country, and Sweden is the least mobile among the Nordic countries. The existing literature has mostly focused on the left panel of the Figure (e.g., Corak 2006), which shows a positive bivariate association between $\beta$ and the private return to schooling. The right panel, which is more novel, depicts a negative association between $\beta$ and public expenditure on education. The Figure shows that the correlation between social mobility and public expenditures for education is at least as strong as the correlation between the private internal return to education and mobility. ${ }^{16}$ When we divide public

14. VAT taxes rose around $15 \%$, and each of the corporate tax rate and the top marginal income tax decreased by $17 \%$. Public expenditure for education as a percentage of gross domestic product (GDP) decreased by $25 \%$ between 1975 and 1985 and by $30 \%$ by the end of the 1980s.

15. In the following Figures we use Corak's most preferred estimate, but we have verified the robustness of our results using the median estimate found in the literature. The nine countries are Denmark, Norway, Finland, Canada, Sweden, Germany, France, the United States, and the United Kingdom. We also add Japan, Spain, and Australia. Some recent papers have estimated the intergenerational income elasticity in Italy, but: (a) the estimates are based on heroic assumptions needed to use intergenerational income data of low quality; (b) the estimates are especially high and (c) even using a more conservative value, Italy is most of the times a major outlier of which we cannot be really confident. The only variable that seems to explain satisfactorily Italy's low degree of mobility is the strength of family ties (high $\rho_{1}$ ).

16. Conditioning on both determinants, the latter turns out to be much more strongly associated with mobility than the former (correlation of -0.43 vs. 0.15 ). 


\section{FIGURE 2}

Private Return to Education versus Public Expenditure in Education
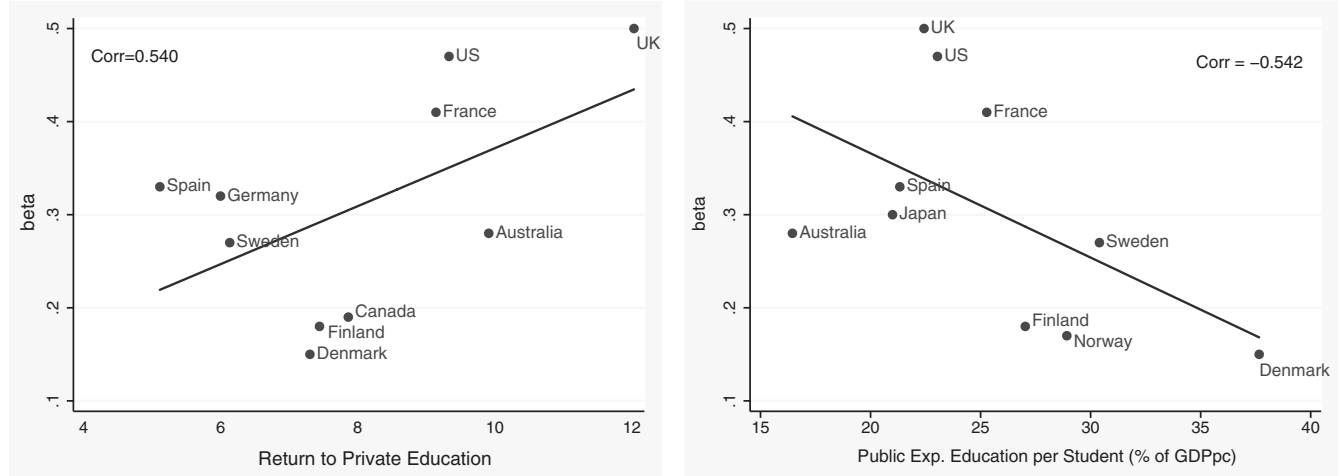

Notes: The left panel shows the relationship between the intergenerational earnings elasticity $\beta$ and the private rate of return to tertiary education. The right panel shows the relationship between the intergenerational earnings elasticity $\beta$ and the public expenditure in education per student as a percentage of per capita GDP. See Appendix B for the data sources.

expenditure in education per student as a percentage of per capita GDP at the primary, secondary and tertiary levels, we find that all are negatively correlated with $\beta$. Notably and consistent with our model, the correlation is stronger at the primary level, where public expenditures are arguably more redistributive. ${ }^{17}$

To obtain a direct measure of political preferences (the parameter $p$ in the model), we use data from the World Value Surveys (WVS). ${ }^{18}$ We focus on the differential in political participation between low income voters and middle and upper income voters. The income classification follows the WVS and is standardized by country. As Table 1 shows, on average, around $33 \%$ of the population is classified as "poor" (low income). Variation across countries is not large. ${ }^{19}$ Political participation can be measured with a variety of variables. In Figure 3 we measure political participation with membership in political parties. The vertical axis in the figure measures inequality in party affiliation, defined as the fraction of middle and upper income voters who are members of political parties divided

17. In contrast, the correlation of $\beta$ with total government spending is -0.05 , and the correlation of $\beta$ with spending on social expenditures is -0.11 . The weakness of these correlations illustrates that it is educational expenditure, rather than other forms of government spending (e.g., unemployment insurance, assistance to poor families, welfare benefits, etc.), that may matter for social mobility.

18. In a previous version of the paper we used voter turnout in elections and union density as additional proxies for $p$. For all cases we find correlations between $p, \mu$, and $\beta$ that are consistent with our model.

19. Sweden and Germany are the two outliers.
TABLE 1

Classification in Poor, Middle, and Rich Per Country: WVS Data

\begin{tabular}{lccc}
\hline & Poor $(\boldsymbol{\%})$ & Middle $(\boldsymbol{\%})$ & Rich $(\boldsymbol{\%})$ \\
\hline Australia & 29 & 34 & 37 \\
Canada & 31 & 36 & 33 \\
Denmark & 31 & 41 & 28 \\
Finland & 33 & 33 & 34 \\
France & 33 & 37 & 30 \\
Germany & 39 & 33 & 28 \\
Japan & 32 & 36 & 32 \\
Norway & 35 & 40 & 25 \\
Spain & 30 & 44 & 26 \\
Sweden & 26 & 44 & 31 \\
The United Kingdom & 35 & 35 & 30 \\
The United States & 35 & 36 & 29 \\
Average & 33 & 37 & 30 \\
\hline
\end{tabular}

Notes: Percentages are rounded to sum to 100 . The numbers refer to the full sample from the Four Wave WVS Data. Actual percentages used in the empirical results may differ slightly depending on the political variable used.

by the fraction of low income voters who are members of political parties. A lower value for this index denotes a relatively more politically active class of low income families and hence a lower $p$. Note that we are not interested in the political participation of the poor per se, but in their participation relative to that one of other income groups in the same country. Our measure of relative participation therefore holds constant other country-specific factors that may affect political participation. 
FIGURE 3

Mobility, Public Education, and Inequality in Political Participation
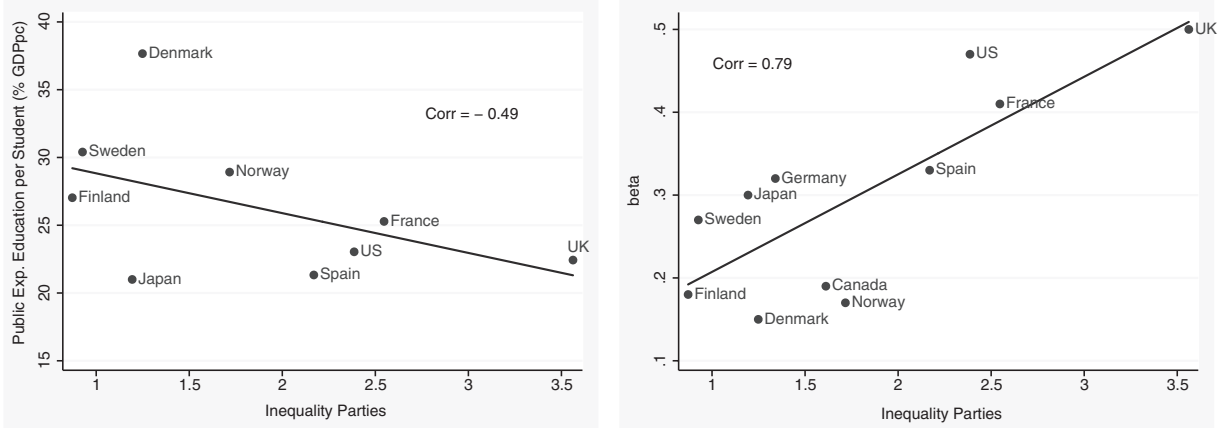

Notes: The left panel shows the relationship between the public expenditure in education per student as a percentage of per capita GDP and the variable "Inequality Parties." The right panel shows the relationship between the intergenerational earnings elasticity $\beta$ and the variable "Inequality Parties." The variable "Inequality Parties" (proxy for $p$ ) is defined as the political party participation rate of the nonpoor (middle and high income) citizens divided by the political party participation rate of the poor citizens. See Appendix B for the data sources.

The correlations in Figure 3 are consistent with the model. The bivariate correlations of the political inequality index with public spending and intergenerational elasticity are, respectively, -0.49 and $0.79 .^{20}$ When we use an alternative measure of the gap in political participation that compares participation by high income voters to participation by low income voters (thus excluding middle income voters), the correlation is even stronger.

The existing literature has argued that one of the most important empirical determinants of social mobility is the rate of return to human capital (see e.g., Solon 1999 and 2004; Corak 2006). When we regress $\beta$ on estimates of the return to schooling, we find that the return to schooling explains only $8 \%$ of the crosscountry variation. Notably, and consistent with our model, our measure of inequality between rich and poor families in political affiliation explains $42 \%$ of the variation in social mobility. ${ }^{21}$ We have repeated this exercise with four other measures of political participation: participation in labor unions, interest in politics, signing petitions, and participating in lawful demonstrations. We find that the patterns are similar to those presented, with the bivariate correlations ranging from 0.43 to 0.63 . (Results available upon request.)

20. This finding is robust to the exclusion of outliers.

21. One of the few studies that attribute cross-country differences in mobility to public policies is Corak and Heitz (1999). The authors conjecture that Canada's progressivity can explain its higher mobility relative to the United States.
In Figure 4, we investigate the relationship between the degree of heterogeneity in a society, public education, and social mobility. Our model predicts that higher ex ante heterogeneity (higher $\left.\operatorname{Var}\left(\ln h_{i}\right)\right)$ should be associated with more public spending and therefore higher social mobility if $p$ is low. If $p$ is high, more heterogeneity should be associated with higher talent $\left(h_{p}\right)$ for the decisive family, and less progressivity. Our empirical proxy for heterogeneity is an index of ethnolinguistic fragmentation measured in $1961 .^{22}$ The upper left panel shows that more diverse countries are associated with less public spending on education. Our model explains this positive correlation only if $p$ is relatively high, which as discussed above is consistent with recent theoretical and empirical literature. The bottom panel shows that the predicted link between heterogeneity and mobility is also supported by the data. The bivariate correlation is 0.26 . Excluding the very heterogeneous and mobile Canada, the correlation increases to 0.67.

Another prediction of the model has to do with the strength of cultural transmission $\rho_{1}$. As a proxy, we use an index of weak family ties. ${ }^{23}$ Weaker family ties proxy for a lower $\rho_{1}$ in our model. In Figure 4, weaker family ties are associated with more public provision of education and more mobility. This lends support

22. The index is defined as one minus the probability that two random persons in some country belong to the same ethnic, linguistic or racial group.

23. The index is due to Alesina and Giuliano (2007). We thank the authors for providing us with their data. 


\section{FIGURE 4}

Mobility, Public Education, Heterogeneity, and Family Ties
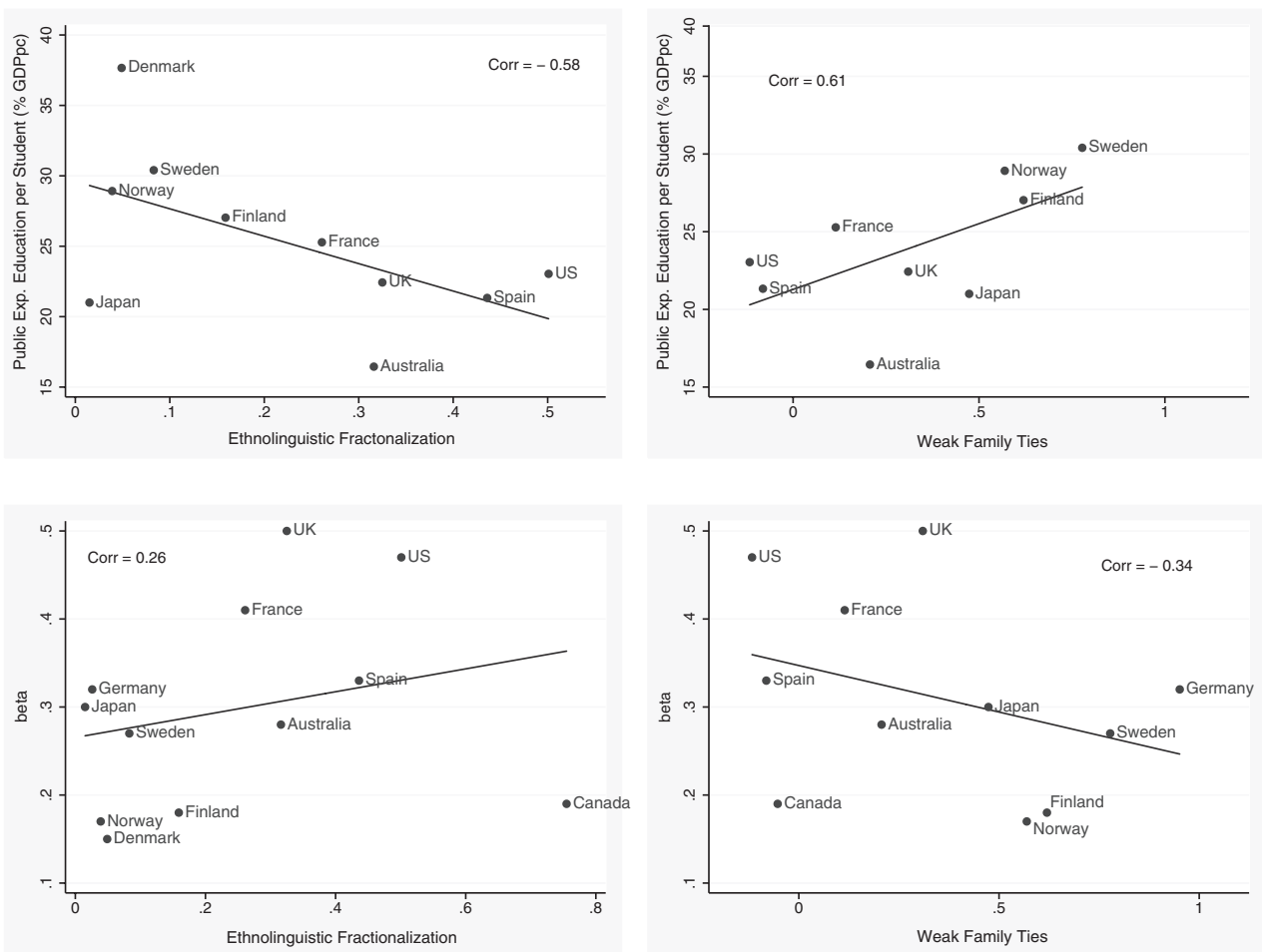

Notes: The left panels show the relationship between the ethnolinguistic fractionalization index, the public expenditure in education per student as a percentage of per capita GDP (upper left), and the intergenerational earnings elasticity $\beta$ (lower left). The right panels show the relationship between the weakness of family ties, the public expenditure in education per student as a percentage of per capita GDP (upper right), and the intergenerational earnings elasticity $\beta$ (lower right). See Appendix B for the data sources.

to the view that strong family ties and strong social policies are substitutes.

We conclude with a final piece of evidence. Becker and Tomes' (1979) original contribution aimed at explaining within a unified economic model the degree of cross-sectional inequality, and its relation with intergenerational inequality. We proxy for cross-sectional inequality in earnings, $\operatorname{Var}\left(y_{i, t}\right)$, with the Gini coefficient for gross earnings. The variance in talent or skills, $\operatorname{Var}\left(\theta_{i, t}\right)$, is proxied by the Gini coefficient for factor income. ${ }^{24}$ In our sample the bivariate association between cross-sectional gross earnings inequality and intergenerational inequality is around 0.72 . Within the context of our model, market variability, $\sigma_{u}^{2}$, explains the lack of perfect correlation. Higher variability

24. These statistics come from Milanovic (2000). increases cross-sectional inequality to a degree that ultimately raises social mobility. ${ }^{25}$

Proposition 1 implies that the ratio of gross earnings over factor inequality should decline when the progressivity of the educational system increases ( $\mu$ decreases). Figure 5 shows a strong association between the ratio of the Gini coefficients and public expenditure in education. It also shows the direct relationship between the deeper determinant $p$ and the ratio of inequalities $\operatorname{Var}\left(y_{i, t}\right) / \operatorname{Var}\left(\theta_{i, t}\right)$ that can rationalize this association. In particular, our model predicts that in societies where the poor participate

25. Björklund and Jäntti (1997) hypothesize that common causes may explain United States's higher intergenerational and cross-sectional inequality relative to Sweden's. Recently, Hassler, Rodriguez Mora, and Zeira (2007) argue that inequality and mobility may be positively correlated if labor market institutions differ significantly across countries or negatively correlated if educational subsidies drive the cross-country variation. 
FIGURE 5

Income and Talent Cross-Sectional Inequality
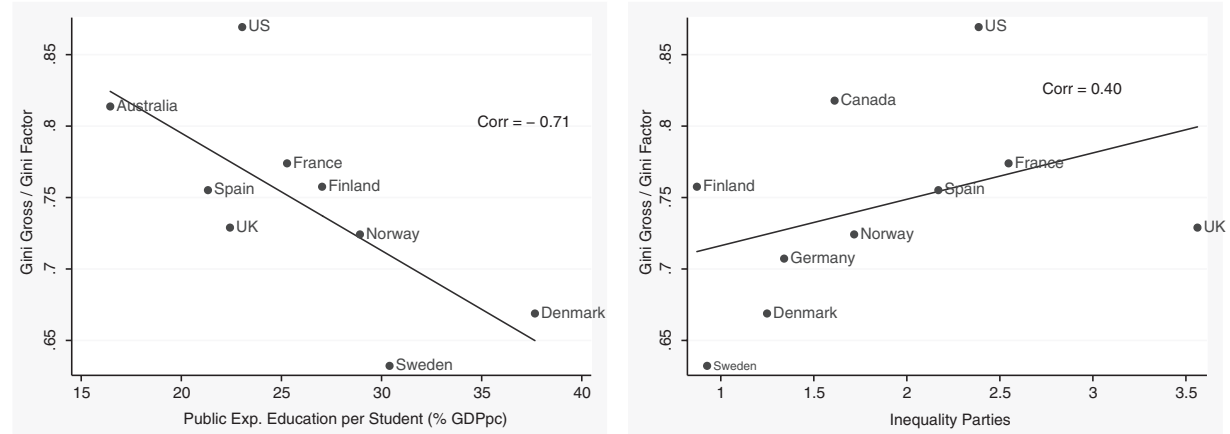

Notes: The left panel shows the relationship between the ratio of Gini coefficients measured at the gross and the factor level and the public expenditure in education per student as a percentage of per capita GDP. The right panel shows the relationship between the ratio of Gini coefficients measured at the gross and the factor level and the variable "Inequality Parties." The variable "Inequality Parties" (proxy for $p$ ) is defined as the political party participation rate of the nonpoor (middle and high income) citizens divided by the political party participation rate of the poor citizens. See Appendix B for the data sources.

more in political parties, redistributive public education takes place and therefore the ratio of income over talent inequality decreases. The right panel of the figure is consistent with this prediction.

\section{CONCLUSION}

Intergenerational mobility emerges from "nature," "nurture," and endogenous public policies. While the previous literature has derived social mobility as a function of the optimizing behavior of utility-maximizing families, in this paper we generalize the structural loglinear social mobility model and endogenize the political process that aggregates conflicting preferences for intergenerational mobility.

Our model provides a structural interpretation of the widely studied GBS reduced-form coefficient $\beta$. This is important because it allows a better understanding of the deeper economic determinants of intergenerational mobility and the role of public policy. We show that public policies generate a trade-off between insurance and incentives. Our model adds to this knowledge by pointing out that even if insurance is relatively costless to provide, a less than perfectly mobile society is possible because of political economy constraints in a world of heterogeneous interests. In other words, two societies may have the same set of dynastic fundamentals such as parental altruism, level of GDP, asset markets, ethnic fragmentation, and cultural traits, but different political institutions, in which case social mobility outcomes will differ.

We conclude with some empirical evidence that lends support to our claim that politicoeconomic variables are likely to be important determinants of cross-country differences in social mobility.

\section{APPENDIX A: DERIVATIONS AND PROOFS}

Derivation of Income and Talent Transmission Equations

First, forward the production function for output, Equation (2), one period and solve for $\Theta_{i, t+1}$ :

$$
\Theta_{i, t+1}=\left(\mu_{t+1}\right)^{-\frac{\alpha}{\mu_{t+1}}}\left(U_{i, t+1}\right)^{-1}\left(Y_{i, t+1}\right)^{\frac{1}{\mu_{t+1}}}
$$

Substitute Equation (A1) into the production function for talent, Equation (6), and solve for investment:

$I_{i, t}=\left(h_{i} V_{i, t+1}\right)^{-1}\left[\left(Y_{i, t+1}\right)^{\frac{1}{\mu_{t+1}}}\left(U_{i, t+1}\right)^{-1}\left(\mu_{t+1}\right)^{-\frac{\alpha}{\mu_{t+1}}}\right]$

If we insert this equation into the budget constraint, $C_{i, t}=Y_{i, t}-I_{i, t}$, we see that the budget is concave for $\mu_{t+1} \leq 1$, strictly when $\mu_{t+1}<1$. Since the utility function (4) is strictly concave, the solution to the problem is unique and interior and is characterized by the first-order condition:

(A3)

$\frac{C_{i, t}}{\gamma Y_{i, t+1}}=\frac{1}{\mu_{t+1}\left(h_{i} V_{i, t+1}\right) U_{i, t+1}}\left(\mu_{t+1}\right)^{-\frac{\alpha}{\mu_{t+1}}}\left(Y_{i, t+1}\right)^{\frac{1}{\mu_{t+1}}-1}$

Substituting $C_{i, t}$ back in the budget constraint, we take the solution for children's income:

$$
\begin{aligned}
Y_{i, t+1}= & \left(\frac{\mu_{t+1}}{\mu_{t+1}+\gamma}\right)^{\mu_{t+1}}\left(h_{i} V_{i, t+1} U_{i, t+1}\right)^{\mu_{t+1}} \\
& \times\left(\mu_{t+1}\right)^{\alpha}\left(Y_{i, t}\right)^{\mu_{t+1}}
\end{aligned}
$$


Taking logs and letting $\mu_{t+1}=\mu$ in Equation (A4) yields the income transition Equation (7) in the text, for the coefficients defined in Equations (8)-(13). From Equation (A2) and the budget constraint we can also take the solution for investment and consumption:

$$
\begin{aligned}
I_{i, t} & =\left(\frac{\mu_{t+1}}{\mu_{t+1}+\gamma}\right) Y_{i, t} \\
C_{i, t} & =\left(\frac{\gamma}{\mu_{t+1}+\gamma}\right) Y_{i, t}
\end{aligned}
$$

To derive the intergenerational transmission equation for talent, we first substitute the production function (2) into the solution (A4). This yields a relationship between sons' income and fathers' talent:

$$
\begin{aligned}
Y_{i, t+1}= & \left(\frac{\mu_{t+1}}{\mu_{t+1}+\gamma}\right)^{\mu_{t+1}}\left(h_{i} V_{i, t+1} U_{i, t+1}\right)^{\mu_{t+1}} \\
& \times\left(\mu_{t+1}\right)^{\alpha}\left[\mu_{t}^{\alpha} \Theta_{i, t}^{\mu_{t}} U_{i, t}^{\mu_{t}}\right]^{\mu_{t+1}}
\end{aligned}
$$

Next, substitute Equation (A7) into Equation (A1) to obtain the solution for talent:

$$
\Theta_{i, t+1}=\left(\frac{\mu_{t+1}}{\mu_{t+1}+\gamma}\right)\left(h_{i} V_{i, t+1}\right)\left(\mu_{t}\right)^{\alpha} U_{i, t}^{\mu_{t}} \Theta_{i, t}^{\mu_{t}}
$$

Taking logs and setting $\mu_{t+1}=\mu_{t}=\mu$ gives the transmission equation for talent:

$$
\theta_{i, t+1}=\lambda_{0, i}+\lambda_{1} \theta_{i, t}+\lambda_{2} v_{i, t+1}+\lambda_{3} u_{i, t}
$$

where:

$$
\begin{aligned}
\lambda_{0, i} & =\lambda_{0}+\lambda_{i} \\
\lambda_{0} & =\ln \left(\frac{\mu}{\mu+\gamma}\right)+\alpha \ln \mu \\
\lambda_{i} & =\ln h_{i} \\
\lambda_{1} & =\mu \\
\lambda_{2} & =1 \\
\lambda_{3} & =\mu
\end{aligned}
$$

The talent transmission equation differs from the income transmission equation due to the coefficients $\lambda_{2}$ and $\lambda_{i}$ (as opposed to the coefficients $\delta_{2}$ and $\delta_{i}$ in the text). These coefficients measure the effects of cultural and genetic endowment on talent and output, respectively. For the case of talent, these effects do not depend on $\mu$, since public policies are imposed on final output.

\section{Expected Income and Talent}

First we show that given a stationary $\mu$, income and talent are stationary processes. Subtracting $\rho_{1} y_{i, t}$ from both sides of the income transmission equation (7), using the definition for $v_{i, t+1}$ in (3), and substituting in the resulting expression the fact that $\rho_{1}\left(\delta_{2} v_{i, t}-y_{i, t}\right)=$ $-\rho_{1}\left(\delta_{0, i}+\delta_{1} y_{i, t-1}+\delta_{3} u_{i, t}\right)$, we can express the income process in Equation (7) as the sum of an $\operatorname{ARMA}(2,1)$ process plus an independent white noise:

(A16)

$$
\begin{aligned}
y_{i, t+1}= & \left(1-\rho_{1}\right)\left(\delta_{0, i}+\delta_{2} \rho_{0}\right)+\left(\delta_{1}+\rho_{1}\right) y_{i, t} \\
& +\left(-\delta_{1} \rho_{1}\right) y_{i, t-1}+\delta_{3} u_{i, t+1}-\delta_{3} \rho_{1} u_{i, t}+\delta_{2} \epsilon_{i, t+1}
\end{aligned}
$$

The process is stationary if the roots of the characteristic equation, $1-\left(\delta_{1}+\rho_{1}\right) x-\left(-\delta_{1} \rho_{1}\right) x^{2}=0$, lie outside the unit circle. The two roots are given by $\phi_{1}=-\frac{1}{\rho_{1}}$ and $\phi_{2}=$ $-\frac{1}{\delta_{1}}=-\frac{1}{\mu}$. Therefore, the log income process is stationary for every family $i$, if $\rho<1$ and $\mu<1$. A similar reasoning applies for the talent process.

The unconditional expectation of log income for family $i$ in Equation (14) in the text is easy to compute by setting $\mathbf{E}\left(y_{i, t+1}\right)=\mathbf{E}\left(y_{i, t}\right)=\mathbf{E}\left(y_{i, t-1}\right)$ in Equation (A16) or (7) All comparative statics for this expectation follow from inspection. From the talent transmission equation (A9), we take the unconditional expectation of $\log$ talent for family $i$ :

$$
\mathbf{E}\left(\theta_{i, t+1} \mid h_{i}\right)=\frac{\rho_{0}+\ln \left(h_{i} \frac{\mu}{\mu+\gamma}\right)+\alpha \ln \mu}{1-\mu}
$$

From the income transmission equation (7) we can compute the conditional expectation of income:

(A18)

$$
\begin{aligned}
\mathbf{E}_{t}\left(y_{i, t+1} \mid h_{i}\right)= & \mathbf{E}\left(y_{i, t+1} \mid h_{i}\right)+\mu\left(y_{i, t}-\mathbf{E}\left(y_{i, t+1} \mid h_{i}\right)\right) \\
& +\mu \rho_{1}\left(v_{i, t}-\rho_{0}\right)
\end{aligned}
$$

where the state of the system includes $\left\{y_{i, t}, \theta_{i, t}, v_{i, t}, u_{i, t}\right\}$, and $\mathbf{E}\left(y_{i, t+1} \mid h_{i}\right)$ is the unconditional expectation given in Equation (14). Similarly for talent we have:

(A19)

$$
\begin{aligned}
\mathbf{E}_{t}\left(\theta_{i, t+1} \mid h_{i}\right)= & \mathbf{E}\left(\theta_{i, t+1} \mid h_{i}\right)+\mu\left(\theta_{i, t}-\mathbf{E}\left(\theta_{i, t+1} \mid h_{i}\right)\right) \\
& +\rho_{1}\left(v_{i, t}-\rho_{0}\right)
\end{aligned}
$$

\section{Variance of Income and Talent}

To derive the unconditional, stationary variance Var $\left(y_{i, t+1} \mid h_{i}\right)$ for dynasty $i$, we impose stationarity in Equation (7) and recall that $u_{i, t+1}$ is independent from $v_{i, t+1}$ and $y_{i, t}$ :

$$
\begin{aligned}
\left(1-\mu^{2}\right) \operatorname{Var}\left(y_{i, t+1} \mid h_{i}\right)= & \mu^{2} \operatorname{Var}\left(v_{i, t+1}\right) \\
& +2 \mu^{2} \operatorname{Cov}\left(y_{i, t}, v_{i, t+1} \mid h_{i}\right) \\
& +\mu^{2} \operatorname{Var}\left(u_{i, t+1}\right)
\end{aligned}
$$

To compute the covariance term, we use the stationarity of the process, the properties of $\epsilon_{i, t+1}$ and the properties of the covariance to take:

$$
\operatorname{Cov}\left(y_{i, t}, v_{i, t+1} \mid h_{i}\right)=\frac{\rho_{1} \mu \sigma_{v}^{2}}{\left(1-\rho_{1} \mu\right)\left(1-\rho_{1}^{2}\right)}
$$

Substituting Equation (A21) into Equation (A20), using the definitions of the variances for $v_{i, t+1}$ and $u_{i, t+1}$ and rearranging we obtain the expression given in the text, Equation (16). The same reasoning yields the variance of talent for family $i$ :

(A22)

$$
\operatorname{Var}\left(\theta_{i, t+1} \mid h_{i}\right)=\frac{1}{1-\mu^{2}} \frac{1+\rho_{1} \mu}{1-\rho_{1} \mu} \frac{\sigma_{v}^{2}}{1-\rho_{1}^{2}}+\frac{\mu^{2}}{1-\mu^{2}} \sigma_{u}^{2}
$$

which is also increasing in $\mu$. Taking the ratio of income's over talent's variance we obtain:

$$
\frac{\operatorname{Var}\left(y_{i, t} \mid h_{i}\right)}{\operatorname{Var}\left(\theta_{i, t} \mid h_{i}\right)}=\frac{\kappa+\sigma_{u}^{2}}{\frac{\kappa}{\mu^{2}}+\sigma_{u}^{2}}
$$

where we define:

$$
\kappa\left(\mu, \rho_{1}\right)=\frac{1+\rho_{1} \mu}{1-\rho_{1} \mu} \frac{\sigma_{v}^{2}}{1-\rho_{1}^{2}}
$$


Because $\mu<1$, the denominator exceeds the numerator in Equation (A23), and the ratio is smaller than unity as claimed in Proposition 1. Next we prove the claim in Proposition 1 that this ratio is increasing in $\mu$. The derivative of the ratio with respect to $\mu$ is proportional to:

$$
\sigma_{u}^{2}\left[\kappa_{1}\left(1-\frac{1}{\mu^{2}}\right)+2 \frac{\kappa}{\mu^{3}}\right]+2 \frac{\kappa^{2}}{\mu^{3}}
$$

where $\kappa_{1}$ is the derivative of $\kappa$ with respect to $\mu$. If the first term in Equation (A24) is positive, then our claim is proven. After some algebra, the sufficient condition reads as:

$$
g\left(\mu, \rho_{1}\right)=\mu\left(\mu^{2}-1-\mu \rho_{1}^{2}\right)>-1
$$

Because the function $g$ has minimum at $-1,\left(\rho_{1}=1\right.$ and $\mu=1$ ), the sufficient condition holds and the claim is proven.

Finally, we consider the inequality in the cross section of families. From Equation (16) it is obvious that $\operatorname{Var}\left(y_{i, t+1}\right)$ increases in $\mu$. For talent we have:

$$
\text { (A26) } \operatorname{Var}\left(\theta_{i, t+1}\right)=\operatorname{Var}\left(\theta_{i, t+1} \mid h_{i}\right)+\frac{1}{(1-\mu)^{2}} \operatorname{Var}\left(\ln h_{i}\right)
$$

where the first term in the right hand side of this equation is given by Equation (A22), and the last term equals the variance of the unconditional expectation of talent (the variance of Equation (A17)). It is straightforward to see that $\operatorname{Var}\left(\theta_{i, t+1}\right)$ also increases in $\mu$. From Equations (16) and (A26), consider the ratio of income over talent inequality in the cross section of families:

$$
\frac{\operatorname{Var}\left(y_{i, t}\right)}{\operatorname{Var}\left(\theta_{i, t}\right)}=\frac{\kappa+\sigma_{u}^{2}+\frac{1+\mu}{1-\mu} \operatorname{Var}\left(\ln h_{i}\right)}{\frac{\kappa}{\mu^{2}}+\sigma_{u}^{2}+\frac{1}{\mu^{2}} \frac{1+\mu}{1-\mu} \operatorname{Var}\left(\ln h_{i}\right)}
$$

where $\kappa$ is defined above. To prove the claim in Proposition 1 that this ratio also increases in $\mu$, let us define $\tau=\frac{1+\mu}{1-\mu}$, with $\tau^{\prime}=\frac{2 \tau}{1-\mu^{2}}$. Then after some tedious but straightforward algebra, the partial derivative of Equation (A27) with respect to $\mu$ is proportional to the following term:

(A28)

$$
\begin{aligned}
\sigma_{u}^{2}\left[\kappa_{1}\left(1-\frac{1}{\mu^{2}}\right)\right. & \left.+2 \frac{\kappa}{\mu^{3}}\right]+2 \frac{\kappa^{2}}{\mu^{3}}+\tau^{\prime} \operatorname{Var}\left(\ln h_{i}\right) \sigma_{u}^{2}\left(1-\frac{1}{\mu^{2}}\right) \\
& +2 \frac{\tau}{\mu^{3}} \operatorname{Var}\left(\ln h_{i}\right)\left(\sigma_{u}^{2}+2 \kappa+\tau \operatorname{Var}\left(\ln h_{i}\right)\right)
\end{aligned}
$$

The first two terms of this expression are positive, as shown in Equations (A24) and (A25). The term $2 \tau \operatorname{Var}\left(\ln h_{i}\right)\left(2 \kappa+\tau \operatorname{Var}\left(\ln h_{i}\right)\right) / \mu^{3}$ is also positive. Therefore, after factoring out the term $\sigma_{u}^{2} \operatorname{Var}\left(\ln h_{i}\right)$, it suffices to show that:

$$
\tau^{\prime}\left(1-\frac{1}{\mu^{2}}\right)+2 \frac{\tau}{\mu^{3}}>0
$$

Plugging in the definitions of $\tau$ and $\tau^{\prime}$ and using the fact that $\mu<1$, we can verify the above inequality.

\section{Intergenerational Correlation of Income and Talent}

In this part, we consider the intergenerational correlation within one dynasty $i$ and treat $h_{i}$ as a time-invariant fixed effect. Because the variance is stationary, the stationary intergenerational correlation in income is equal to:

$$
\begin{aligned}
\operatorname{Corr}\left(y_{i, t+1}, y_{i, t} \mid h_{i}\right) & =\frac{\operatorname{Cov}\left(y_{i, t+1}, y_{i, t} \mid h_{i}\right)}{\operatorname{Var}\left(y_{i, t} \mid h_{i}\right)} \\
& =\mu+\mu \frac{\operatorname{Cov}\left(y_{i, t}, v_{i, t+1} \mid h_{i}\right)}{\operatorname{Var}\left(y_{i, t} \mid h_{i}\right)}
\end{aligned}
$$

where we have used Equation (7) and the properties of $u_{i, t+1}$. To obtain the expression (19) in the text, we insert the variance from Equation (16) and the covariance from Equation (A21) into the correlation shown in Equation (A30). We can differentiate Equation (19):

(A31)

$$
\begin{aligned}
& \frac{\partial \operatorname{Corr}\left(y_{i, t+1}, y_{i, t} \mid h_{i}\right)}{\partial \mu} \propto \sigma_{v}^{4}\left(1-\rho_{1}^{2}\right)+\sigma_{u}^{4}\left(1-\rho_{1}^{2}\right)^{2} \\
& \times\left(1-\rho_{1} \mu\right)^{2}+\sigma_{v}^{2} \sigma_{u}^{2}\left(1-\rho_{1}^{2}\right)\left(2\left(1-\rho_{1} \mu\right)+\rho_{1}\left(1-\mu^{2}\right)\right)
\end{aligned}
$$

Because all terms are positive, the correlation is increasing in $\mu$ and the claim in Proposition 1 is proven. A similar reasoning shows that the stationary intergenerational correlation of talent is:

(A32) $\operatorname{Corr}\left(\theta_{i, t+1}, \theta_{i, t} \mid h_{i}\right)$

$$
=\frac{\left(\mu+\rho_{1}\right) \sigma_{v}^{2}+\mu^{3}\left(1-\rho_{1} \mu\right)\left(1-\rho_{1}^{2}\right) \sigma_{u}^{2}}{\left(1+\rho_{1} \mu\right) \sigma_{v}^{2}+\mu_{t}^{2}\left(1-\rho_{1} \mu\right)\left(1-\rho_{1}^{2}\right) \sigma_{u}^{2}}
$$

Differently from income, the intergenerational correlation of talent has ambiguous comparative static in $\mu$. A more progressive policy decreases both the covariance and the variance of income and talent. For income, the rate of decrease in the variance is smaller than that of the covariance and the comparative static is unambiguous. But in the case of talent, the covariance is not sufficiently decreasing because talent is not directly affected by $\mu$. We can show that the intergenerational correlation in talent is increasing in $\mu$ provided that $\sigma_{u}^{2}$ is not too large relative to $\sigma_{v}^{2}$.

Finally, we prove the claim in Proposition 1 that the ratio of intergenerational correlations is smaller than one and increasing in $\mu$. First, consider the ratio:

(A33)

$$
\begin{aligned}
& \operatorname{Corr}\left(y_{i, t+1}, y_{i, t} \mid h_{i}\right) / \operatorname{Corr}\left(\theta_{i, t+1}, \theta_{i, t} \mid h_{i}\right)= \\
& \left(\mu+\rho_{1}\right)\left(1+\rho_{1} \mu\right) \sigma_{v}^{4}+\mu^{3}\left(1-\rho_{1} \mu\right)^{2}\left(1-\rho_{1}^{2}\right)^{2} \sigma_{u}^{4} \\
& +\sigma_{v}^{2} \sigma_{u}^{2}\left(1-\rho_{1} \mu\right)\left(1-\rho_{1}^{2}\right)\left(\mu^{2}\left(\mu+\rho_{1}\right)+\mu+\mu^{2} \rho_{1}\right) \\
& \left(\mu+\rho_{1}\right)\left(1+\rho_{1} \mu\right) \sigma_{v}^{4}+\mu^{3}\left(1-\rho_{1} \mu\right)^{2}\left(1-\rho_{1}^{2}\right)^{2} \sigma_{u}^{4} \\
& +\sigma_{v}^{2} \sigma_{u}^{2}\left(1-\rho_{1} \mu\right)\left(1-\rho_{1}^{2}\right)\left(\mu^{3}\left(1+\rho_{1} \mu\right)+\mu+\rho_{1}\right)
\end{aligned}
$$

The difference between the last term in the denominator and the numerator is $\sigma_{v}^{2} \sigma_{u}^{2}\left(1-\rho_{1}^{2}\right)\left(1-\rho_{1} \mu\right) \rho_{1}(\mu-1)^{2}$. This difference is positive because $\sigma_{v}^{2}>0, \sigma_{u}^{2}>0$ and $\rho_{1}<$ 1. As a result, the expression in Equation (A33) is smaller than unity, strictly when $\mu<1$, as claimed in Proposition 1 . In addition, the ratio is increasing in $\mu$. To see this, rewrite the ratio as:

$$
\begin{gathered}
\operatorname{Corr}\left(y_{i, t+1}, y_{i, t} \mid h_{i}\right) / \operatorname{Corr}\left(\theta_{i, t+1}, \theta_{i, t} \mid h_{i}\right)= \\
\left(\mu+\rho_{1}\right) \frac{1+\rho_{1} \mu}{\left(1-\rho_{1} \mu\right)^{2}} \sigma_{v}^{4}+\mu^{3}\left(1-\rho_{1}^{2}\right)^{2} \sigma_{u}^{4} \\
+\sigma_{v}^{2} \sigma_{u}^{2} \frac{1-\rho_{1}^{2}}{1-\rho_{1} \mu}\left(\mu^{2}\left(\mu+\rho_{1}\right)+\mu+\mu^{2} \rho_{1}\right) \\
\left(\mu+\rho_{1}\right) \frac{1+\rho_{1} \mu}{\left(1-\rho_{1} \mu\right)^{2}} \sigma_{v}^{4}+\mu^{3}\left(1-\rho_{1}^{2}\right)^{2} \sigma_{u}^{4} \\
+\sigma_{v}^{2} \sigma_{u}^{2} \frac{1-\rho_{1}^{2}}{1-\rho_{1} \mu}\left(\mu^{3}\left(1+\rho_{1} \mu\right)+\mu+\rho_{1}\right)
\end{gathered}
$$

Denote by $N$ the numerator and by $D$ the denominator of this expression. The ratio of correlations increases in $\mu$ if and only if the derivate $N^{\prime} D-D^{\prime} N$ is positive. Since the denominator exceeds the numerator, $D>N$, it suffices to show that $N^{\prime}>D^{\prime}>0$. From Equation (A34) it 
is evident that both terms increase in $\mu$. From $N-D=$ $-\sigma_{v}^{2} \sigma_{u}^{2} \frac{1-\rho_{1}^{2}}{1-\rho_{1} \mu} \rho_{1}(\mu-1)^{2}$, we take $N^{\prime}-D^{\prime}=-\sigma_{v}^{2} \sigma_{u}^{2}(1-$ $\left.\rho_{1}^{2}\right) \rho_{1} \frac{(\mu-1)(2-\rho \mu-\rho)}{\left(1-\rho_{1} \mu\right)^{2}}>0$, which proves the claim.

\section{Proof of Proposition 2}

Using the consumption function in Equation (21) and the conditional expectation of income in Equation (15), we can express the indirect utility function as:

(A35)

$$
\begin{aligned}
& W\left(\mu_{t+1} ; h_{i}, y_{i, t}, v_{i, t}\right) \\
& =y_{i, t}+\ln \frac{\gamma}{\gamma+\mu_{t+1}} \\
& +\frac{1}{\gamma}\left(\alpha \ln \mu_{t+1}+\mu_{t+1}\left(\ln \left(\frac{\mu_{t+1}}{\gamma+\mu_{t+1}}\right)+\rho_{0}\left(1-\rho_{1}\right)\right)\right) \\
& +\frac{\mu_{t+1}}{\gamma} Q_{i, t}
\end{aligned}
$$

where $Q_{i, t}=y_{i, t}+\rho_{1} v_{i, t}+\ln h_{i}$ is family $i$ 's income potential at time $t$. Differentiating $W$ with respect to $\mu_{t+1}$ we take:

$$
\frac{\partial W}{\partial \mu_{t+1}}=W_{1}+\frac{1}{\gamma}\left[W_{2}+W_{3}+W_{4}+W_{5}+Q_{i, t}\right]
$$

In this expression, the term $W_{1}=-\frac{1}{\mu_{t+1}+\gamma}<0$ captures the intertemporal trade-off, $W_{2}=\ln \left(\frac{\mu_{t+1}}{\mu_{t+1}+\gamma}\right)<0$ measures the beneficial insurance effects of public policy, $W_{3}=\frac{\gamma}{\mu_{t+1}+\gamma}>0$ is the term associated with the distortions in investment, $W_{4}=\frac{\alpha}{\mu_{t+1}}>0$ is the direct output cost, $W_{5}=\rho_{0}\left(1-\rho_{1}\right)>0$ shows that insurance is less beneficial the higher is the long-run level of the endowment $v_{i, t}$, and $Q_{i, t}$ is defined above. Differentiating Equation (A36) with respect to $\mu_{t+1}$ we have:

$$
\frac{\partial W^{2}}{\partial \mu_{t+1}^{2}} \propto \frac{1}{\gamma+\mu_{t+1}}-\frac{\alpha}{\mu_{t+1} \gamma}
$$

A sufficient condition for single-peaked preferences is the strict concavity of the indirect utility. This requires that $\frac{\mu_{t+1} \gamma}{\mu_{t+1}+\gamma}<\alpha$. Since the left hand side of this inequality is bounded above by 1 , the first part of the claim in Proposition 2 follows. For the second part of the Proposition, set $\partial W / \partial \mu_{t+1}$ equal to zero, and use the implicit function theorem and the concavity of $W$ in an interior optimum:

$$
\frac{\partial \mu_{t+1}}{\partial Q_{i, t}} \propto \frac{\partial W^{2}}{\partial \mu_{t+1} \partial Q_{i, t}}=\frac{1}{\gamma}>0
$$

\section{Proof of Proposition 3}

If $0<\mu_{i, t+1}<1$ is the most preferred public policy for a dynasty with parameter $Q_{i, t}$, then it necessarily satisfies the first-order condition, $\partial W / \partial \mu_{t+1}=0$, where the derivative is given by Equation (A36). In addition, if $\alpha>1$, then $W$ is globally concave, and hence any solution to the first order condition will be the unique optimum. Since the implicit function theorem applies, the comparative static $\partial \mu_{t+1} / \partial z$ has the same sign as the cross partial $\partial^{2} W\left(\mu_{t+1}\left(h_{i}\right)\right) / \partial\left(\mu_{t+1}\right) \partial z$.

Therefore, $\frac{\partial^{2} W\left(\mu_{t+1}\right)}{\partial \mu_{t+1} \partial \alpha} \propto 1 / \mu_{i, t+1}>0, \frac{\partial^{2} W\left(\mu_{t+1}\right)}{\partial \mu_{t+1} \partial \rho_{0}} \propto 1-$ $\rho_{1}>0, \frac{\partial^{2} W\left(\mu_{t+1}\right)}{\partial \mu_{t+1} \partial \rho_{1}} \propto v_{i, t}-\rho_{0}$, and $\frac{\partial^{2} W\left(\mu_{t+1}\right)}{\partial \mu_{t+1} \partial Q_{i, t}}=1 / \gamma>0$.
Since the most preferred policy $\mu_{t+1}$ of low $Q_{i, t}$ families is lower, it follows that when the position of the decisive agent $p$ decreases, $\mu_{t+1}$ also decreases. For the parameter that expresses the degree of parental altruism, after some algebra and using the first-order condition at optimum, we have:

$$
\frac{\partial^{2} W\left(\mu_{t+1}\right)}{\partial \mu_{t+1} \partial \gamma}=-\frac{1}{\gamma}<0
$$

We briefly discuss the remaining comparative statics. First, social mobility is lower in societies with higher longrun income (higher $\rho_{0}$ ). At first glance, this may appear counterfactual, since the conjecture is that in less developed economies, social mobility is lower (Solon, 2002). However, this could be because less developed economies have poorer tax collection technologies (high $\alpha$ ) and limited expansion of voting rights (high $p$ ).

Second, in the original Becker and Tomes (1979) model, altruistic parents invest more in the human capital of their children, which strengthens the intergenerational transmission and lowers social mobility. This result also holds in our model, but it takes place through a different mechanism. ${ }^{26}$ Because a lower $\mu$ distorts fathers' investment decisions, a higher $\mu$ (less progressivity) redistributes resources in favor of the future generation. Hence, more altruistic fathers transfer more resources to the next generation by choosing a higher $\mu$.

Third, if the decisive voter is temporarily well-endowed in family ability $\left(v_{i, t}>\rho_{0}\right)$, then cultural persistence decreases the progressivity of the public policy. This result is consistent with the hypothesis that stronger family ties offer insurance and therefore "crowd out" the scope for social insurance.

Fourth, given the income potential $Q_{p, t}$, the parameters $\sigma_{v}^{2}$ and $\sigma_{u}^{2}$ do not affect the optimal $\mu$. Because of the assumed $\log -\log$ specification, substitution and income effects cancel off, and consumption and investment are constant fractions of output, independently of the properties of the shocks. In a more general specification of preferences, the scope for insurance will increase when endowment and market luck become more variable. Nevertheless, the properties of the two shocks can matter indirectly for $\mu$, through the evolution of the income potential in the next period $Q_{p, t+1}$. Therefore, the persistence and volatility of the equilibrium $\mu$ are affected by cultural, genetic, and market randomness.

\section{Proof of Proposition 4}

First, we examine a stationary state with $\mu_{t+1}=\mu_{t}$. The population coefficient vector is defined as the argument that minimizes the least squares problem in the population:

$$
(a, \beta)=\arg \min _{a, \beta} \mathbf{E}\left[\left(y_{i, t+1}-a-\beta y_{i, t}\right)^{2}\right]
$$

The well known formula for the population slope is given by:

$$
\begin{aligned}
\beta & =\frac{\operatorname{Cov}\left(y_{i, t+1}, y_{i, t}\right)}{\operatorname{Var}\left(y_{i, t}\right)}=\operatorname{Corr}\left(y_{i, t+1}, y_{i, t}\right) \\
& =\frac{\operatorname{Cov}\left(\delta_{0}+\mu_{t+1}\left(\ln h_{i}+y_{i, t}+v_{i, t+1}+u_{i, t+1}\right), y_{i, t}\right)}{\operatorname{Var}\left(y_{i, t}\right)}
\end{aligned}
$$

26. In our model, altruistic fathers invest more in their children's human capital, holding constant $\mu$. However, because of the log-linear specification, altruism does not enter directly in the intergenerational transmission equation. See Solon (2004) for a similar result. 
which, from the imposed stationarity $\operatorname{Var}\left(y_{i, t+1}\right)=$ $\operatorname{Var}\left(y_{i, t}\right)$, also equals the cross-sectional intergenerational correlation, $\operatorname{Corr}\left(y_{i, t+1}, y_{i, t}\right)$. Recalling the properties of $u_{i, t+1}$ and $\epsilon_{i, t+1}$, we have:

(A42)

$$
\beta=\mu_{t+1}\left(1+\frac{\operatorname{Cov}\left(v_{i, t+1}, y_{i, t}\right)+\operatorname{Cov}\left(\ln h_{i}, y_{i, t}\right)}{\operatorname{Var}\left(y_{i, t}\right)}\right)
$$

The first covariance in the numerator is given by Equation (A21), because the fixed effect $h_{i}$ is orthogonal to the $\epsilon_{i, t+1}$ and hence the $v_{i, t+1}$ process. The stationary covariance between the family-fixed effect and income is given by:

$$
\operatorname{Cov}\left(\ln h_{i}, y_{i, t}\right)=\frac{\mu_{t+1}}{1-\mu_{t+1}} \operatorname{Var}\left(\ln h_{i}\right)
$$

Putting all pieces together and setting $\mu_{t+1}=\mu_{t}=\mu$, yields the expression for $\beta$ in Proposition 4 .

Next, we show that $\beta$ is increasing in $\mu$. Using the variances in Equations (16)-(18) yields:

$$
\beta=\mu\left(\frac{\frac{\mu}{1-\mu^{2}} \frac{\mu+\rho_{1}}{1-\rho_{1} \mu} \frac{\sigma_{v}^{2}}{1-\rho_{1}^{2}}+\frac{\mu^{2}}{1-\mu^{2}} \sigma_{u}^{2}+\frac{1}{\mu} \operatorname{Var}\left(\mathbf{E}\left(y_{i, t+1} \mid h_{i}\right)\right)}{\frac{\mu^{2}}{1-\mu^{2}} \frac{1+\rho_{1} \mu}{1-\rho_{1} \mu} \frac{\sigma_{v}^{2}}{1-\rho_{1}^{2}}+\frac{\mu^{2}}{1-\mu^{2}} \sigma_{u}^{2}+\operatorname{Var}\left(\mathbf{E}\left(y_{i, t+1} \mid h_{i}\right)\right)}\right)
$$

or

$$
\begin{array}{r}
\left(\mu+\rho_{1}\right) \sigma_{v}^{2}+\mu\left(1-\rho_{1} \mu\right)\left(1-\rho_{1}^{2}\right) \sigma_{u}^{2} \\
\beta=\frac{+\left(1-\rho_{1}^{2}\right)(1+\mu) \frac{1-\rho_{1} \mu}{1-\mu} \operatorname{Var}\left(\ln h_{i}\right)}{\left(1+\rho_{1} \mu\right) \sigma_{v}^{2}+\left(1-\rho_{1} \mu\right)\left(1-\rho_{1}^{2}\right) \sigma_{u}^{2}} \\
+\left(1-\rho_{1}^{2}\right)(1+\mu) \frac{1-\rho_{1} \mu}{1-\mu} \operatorname{Var}\left(\ln h_{i}\right)
\end{array}
$$

Consider the last term in the numerator and the denominator. Because $\frac{1-\rho_{1} \mu}{1-\mu}$ is increasing in $\mu$, this term also increases in $\mu$. So, adding the same, increasing in $\mu$, term both in the numerator and the denominator, tends, holding constant all other terms, to produce an increasing $\beta$, because the numerator is smaller than the denominator. Furthermore, $\beta$ will increase more in $\mu$ due to this last term, when $\operatorname{Var}\left(\ln h_{i}\right)$ is higher. Hence, consider $\operatorname{Var}\left(\ln h_{i}\right)=0$. In this case (A45) collapses to the dynastic correlation in Equation (19). Previously in this Appendix, we showed that this correlation is increasing in $\mu$, which completes the proof of the claim that $\beta$ increases in $\mu$.

Differentiating Equation (A45) with respect to $\sigma_{u}$, we can show that:

$$
\text { (A46) } \begin{aligned}
& \frac{\partial \beta}{\partial \sigma_{u}^{2}} \propto\left(\mu^{2}-1\right) \\
& \times\left(\rho_{1} \sigma_{v}^{2}+\left(1-\rho_{1}^{2}\right)(1+\mu) \frac{1-\rho_{1} \mu}{1-\mu} \operatorname{Var}\left(\ln h_{i}\right)\right) \leq 0
\end{aligned}
$$

as claimed in Proposition 4. Differentiating Equation (A45) with respect to $\operatorname{Var}\left(\ln h_{i}\right)$, we obtain

$$
\begin{aligned}
& \frac{\partial \beta}{\partial \operatorname{Var}\left(\ln h_{i}\right)} \propto\left(1-\mu^{2}\right) \\
& \quad\left(\left(1-\rho_{1}\right) \sigma_{v}^{2}+\left(1-\rho_{1}^{2}\right)\left(1-\rho_{1}\right) \sigma_{u}^{2}\right) \geq 0
\end{aligned}
$$

The comparative statics of $\beta$ with respect to $\alpha, p$, $Q_{p, t}, \rho_{1}$ and $\gamma$ follow from Proposition 3 and the result $\partial \beta / \partial \mu>0$. Finally, we have verified numerically that $\mu$ is non-monotonic in $\rho_{1}$ and $\sigma_{v}^{2}$ for various combinations of parameters.

Finally, for the second part of the Proposition we use the new equilibrium $\mu_{t+1}$ in the $\operatorname{AR}(1)$ process for income in Equation (7). $\operatorname{Var}\left(y_{i, t}\right)$ is given by Equation (17) in the text for policy $\mu_{t}$. The formulas for $\operatorname{Cov}\left(\ln h_{i}, y_{i, t}\right)$ and $\operatorname{Cov}\left(v_{i, t+1}, y_{i, t}\right)$ are taken by assuming that before the structural break the economy is in a steady state with $\mu_{t}=\mu_{s}$ for all $s<t+1$.

\section{APPENDIX B: DATA}

Social Mobility: Data for the intergenerational earnings elasticity is taken from http://www.iza.org/index_html?lang= en\&mainframe $=\mathrm{http} \% 3 \mathrm{~A} / / \mathrm{www}$.iza.org/en/webcontent/ personnel/photos/index_html\%3Fkey\%3D83\&topSelect= personnel\&subSelect=fellows Corak's (2006) meta-analysis. For Australia we use estimates from Leigh (2007). For Japan we use estimates from Lefranc, Ojima and Yoshida (2008). For Spain we use estimates from d'Addio (2007).

Private Return to Education: Taken from http://www.olis. oecd.org/olis/2007doc.nsf/LinkTo/NT000059E2/\$FILE/ JT03238193.PDF Boarini and Strauss (2007), Table 3. Calculated as the simple average in every country for the years available (males and females).

Total Government Spending and Social Welfare Spending: Government spending denotes central government consumption and investment. Social Welfare denotes consolidated government spending on social services as percentage of GDP. This data is taken from http://www.igier.unibocconi.it/whos.php?vedi=1169\&tbn=albero\&id_folder $=$ 177 Persson and Tabellini (2003). The variables are averaged over the 1960-1998 period.

Public Education: Data taken from http://www.oecdwash. org/PUBS/ELECTRONIC/epels.htm\#edustat OECD's Online Education Database. The series extracted are Public education expenditure as \% of GDP, Public education expenditure per student (\% of p.c. GDP), at all levels, and Public education expenditure per student (\% of p.c.GDP), at the primary, secondary, and tertiary level. For every country we average the series for all available years in periods 1970-2007.

Ethnolinguistic fractionalization (ELF): Taken from http:// weber.ucsd.edu/ proeder/elf.htm Roeder (2001). The ELF index is defined as one minus the probability that two randomly chosen persons from a population belong to the same ethnic, linguistic or racial group. A higher ELF index denotes a more heterogeneous population. The value taken refers to the year 1961 .

Gini Coefficient: The Gini coefficients at the factor and the gross earnings level are taken from http://www.sciencedirect. com/science/article/B6V97-40X8GBB-1/2/ a10cf47920052f9f940852f3781bc71c Milanovic (2000) and are averaged across all available periods for any given country.

Weak Family Ties: Taken from http://ftp.iza.org/dp2750. pdf Alesina and Giuliano (2007).

Political Inequality Variables: Taken from the Four Wave http://www.worldvaluessurvey.org/World Values Survey. The political participation variables that we use are recoded in binary form as follows: Interested in Politics (WVS code: E023; recoded as 1 for responders that answered 1 or 2 , and 0 otherwise); Belong to Political 
Party (A068; already binary); Sign Petitions (E025; 1 if the responder answered yes and 0 otherwise); Participation in Lawful Demonstration $(E 027 ; 1$ if the responder answered 1 or 2, 0 otherwise); Belong to Labor Union (A067; already binary). The income classification follows the variable $X 047 R$; see also Table 1 .

\section{REFERENCES}

Aaronson, D., and B. Mazumder. "Intergenerational Economic Mobility in the US: 1940 to 2000." Journal of Human Resources, 43(1), 2008, 139-72.

Alesina, A., and P. Giuliano. "The Power of the Family." NBER Working Paper, No. 13051, 2007.

. "Preferences for Redistribution." NBER Working Paper, No. 14825, 2009.

Alesina, A., and E. Glaeser. Fighting Poverty in the US and Europe: A World of Difference. Oxford, UK: Oxford University Press, 2004.

Alesina, A., and D. Rodrik. "Distributive Politics and Economic Growth." Quarterly Journal of Economics, 109, 1994, 465-90.

Atkeson, A., and R. Lucas. "On Efficient Distribution with Private Information." Review of Economic Studies, 59, 1992, 427-53.

Becker, G., and N. Tomes. "An Equilibrium Theory of the Distribution of Income and Intergenerational Mobility." Journal of Political Economy, 87, 1979, 1153-89. . "Human Capital and the Rise and Fall of Families." Journal of Labor Economics, 4, 1986, S1-39.

Benabou, R. "Inequality and Growth," in NBER Macroeconomics Annual, edited by B. Bernanke and J. Rotemberg. Cambridge: MIT Press, 1996, 11-73.

. "Unequal Societies: Income Distribution and the Social Contract." American Economic Review, 90, 2000, 96-129.

Benabou, R., and Ok, E. "Social Mobility and the Demand for Redistribution: The POUM Hypothesis." Quarterly Journal of Economics, 116(2), 2001, 447-87.

Bernasconi, M., and P. Profeta. "Redistribution or Education? The Political Economy of the Social Race." CESifo Working Paper No. 1934, 2007.

Björklund, A., and M. Jäntti. "Intergenerational Income Mobility in Sweden Compared to the United States." American Economic Review, 87, 1997, 1009-18.

Blanden, J., P. Gregg, and L. Macmillan. "Accounting for Intergenerational Income Persistence: Noncognitive Skills, Ability and Education." Economic Journal, 117(1), 2007, C43-60.

Boarini, R., and H. Strauss. "The Private Internal Rates of Return to Tertiary Education: New Estimates for 21 OECD Countries." OECD Economics Department Working Papers, No. 591, 2007.

Campante, F. "Redistribution in a Model of Voting and Campaign Contributions." Mimeo, Harvard University, 2007.

Checchi, D., A. Ichino, and A. Rustichini. "More Equal But Less Mobile? Education Financing and Intergenerational Mobility in Italy and the US." Journal of Public Economics, 74, 1999, 351-93.

Corak, M. "Do Poor Children Become Poor Adults? Lessons From a Cross Country Comparison of Generational Earnings Mobility." Research on Economic Inequality, 13(1), 2006, 143-88.

Corak, M., and A. Heitz. "The Intergenerational Earnings and Income Mobility of Canadian Men: Evidence from Longitudinal Income Tax Data." Journal of Human Resources, 34(3), 1999, 504-33.

d'Addio, A. C. "Intergenerational Transmission of Disadvantage: Mobility or Immobility Across Generations?"
OECD Social Employment and Migration Working Papers, No. 52, 2007.

Davies, J., J. Zhang, and J. Zeng. "Intergenerational Mobility under Private vs. Public Education." Scandinavian Journal of Economics, 107(3), 2005, 399-417.

Farhi, E., and I. Werning. "Inequality and Social Discounting." Journal of Political Economy, 115(3), 2007, $365-402$.

Fernandez, R., and R. Rogerson. "Public Education and Income Distribution: A Dynamic Quantitative Evaluation of Education-Finance Reform." American Economic Review, 88(4), 1998, 813-33.

Glomm, G., and B. Ravikumar. "Public vs. Private Investment in Human Capital: Endogenous Growth and Income Inequality." Journal of Political Economy, 100, 1992, 818-34.

Goldberger, A. "Economic and Mechanical Models of Intergenerational Transmission." American Economic Review, 79(3), 1989, 504-13.

Hassler, J., J. V. Rodriguez Mora, K. Storesletten, and F. Zilibotti. "The Survival of the Welfare State." American Economic Review, 93(1), 2003, 87-112.

Hassler, J., J. V. Rodriguez Mora, and J. Zeira. "Inequality and Mobility." Journal of Economic Growth, 12, 2007, 235-59.

Karabarbounis, L. “One Dollar, One Vote.” Mimeo, University of Chicago Booth School of Business. 2010.

Krusell, P., V. Quadrini, and J.-V. Rios-Rull. "PoliticoEconomic Equilibrium and Economic Growth." Journal of Economic Dynamics and Control, 21, 1997, $243-72$.

Lee, C.-I., and G. Solon. "Trends in Intergenerational Income Mobility.” NBER Working Paper, No. 12007, 2006.

Lefranc, A., F.Ojima, and T. Yoshida. "The Intergenerational Transmission of Income and Education: A Comparison of Japan and France." Working Paper, EUI, 2008.

Leigh, A. "Intergenerational Mobility in Australia." B.E. Journal of Economic Analysis and Policy, 7(2), Article 6, 2007.

Lindert, P. Growing Public: Social Spending and Economic Growth Since the Eighteenth Century, Vol. 1 and 2. New York, NY: Cambridge University Press, 2004.

Loury, G. "Intergenerational Transfers and the Distribution of Earnings." Econometrica, 49(4), 1981, 843-7.

Mayer, S., and L. Lopoo. "Has the Intergenerational Transmission of Economic Status Changed?" Journal of Human Resources, 40(1), 2005, 169-85.

Mazumder, B. "Fortunate Sons: New Estimates of Intergenerational Mobility in the U.S. Using Social Security Earnings Data." Review of Economics and Statistics, $87(2), 2005,235-55$.

Mazumder, B. "Trends in Intergenerational Mobility." Industrial Relations, 46(1), 2007, 1-6.

Milanovic, B. "The Median Voter Hypothesis, Income Inequality and Income Redistribution: An Empirical Test with the Required Data." European Journal of Political Economy, 16, 2000, 367-410.

Mulligan, C. Parental Priorities and Economic Inequality. Chicago, IL: The University of Chicago Press, 1997.

Pekkarinen, T., R. Uusitalo, and S. Kerr. "School Tracking and Intergenerational Income Mobility: Evidence from the Finnish Comprehensive School Reform.” Mimeo, Helsinki School of Economics, 2008.

Persson, T., and G. Tabellini. "Is Inequality Harmful for Growth?" American Economic Review, 84(3), 1994, $600-21$.

. The Economic Effects of Constitutions. Cambridge, MA: MIT Press, 2003. 
Phelan, C. "Opportunity and Social Mobility." Review of Economic Studies, 73, 2006, 487-504.

Piketty, T. "Social Mobility and Redistributive Politics." Quarterly Journal of Economics, 110(3), 1995, 551-84.

. "Theories of Persistent Inequality and Intergenerational Mobility," in Handbook of Income Distribution, Vol. 1, edited by A. B. Atkinson and F. Bourguignon. North-Holland, 2000, 429-76.

Saint-Paul, G., and T. Verdier. "Education, Democracy and Growth." Journal of Development Economics, 42, 1993, 399-407.

Solon, G. "Intergenerational Income Mobility in the United States." American Economic Review, 82, 1992, 393-408.
"Intergenerational Mobility in the Labor Market," in Handbook of Labor Economics, Vol. 3B, edited by O. C Ashenfelter and D. Card. New York, NY: Elsevier Science Press, 1999, 1762-96.

. "Cross-Country Differences in Intergenerational Earnings Mobility." Journal of Economic Perspectives, 16(3), 2002, 59-66.

"A Model of Intergenerational Mobility Variation over Time and Place," in Generational Income Mobility in North America and Europe, edited by M. Corak. Cambridge University Press, 2004, 38-47.

Zimmerman, D. "Regression Toward Mediocrity in Economic Stature." American Economic Review, 82, 1992, 409-29. 